\title{
FOUR DECADES OF ORGANIC CHEMISTRY OF ClOSO-BORANES: A SYNTHETIC TOOLBOX FOR CONSTRUCTING LIQUID CRYSTAL MATERIALS. A REVIEW
}

\section{Piotr KASZYNSKI}

Organic Materials Research Group, Chemistry Department, Vanderbilt University, Nashville, TN 37235,U.S.A.; e-mail: piotr@ctrvax.vanderbilt.edu

Dedicated to Dr Stanislav Heřmánek on the occasion of his 70th birthday in recognition of his outstanding contributions to the areas of borane chemistry and NMR spectroscopy.

1. Introduction . . . . . . . . . . . . . . . . . . . . . . . . . . . . 895

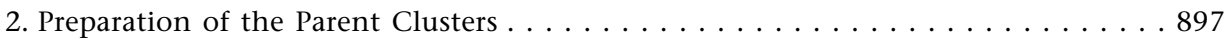

3. Functionalization of the Ten- and Twelve-Vertex Clusters . . . . . . . . . . 900

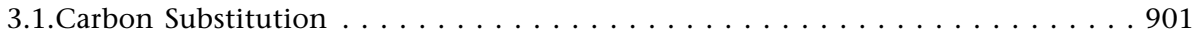

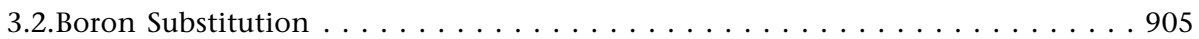

4. Functional Group Transformations . . . . . . . . . . . . . . . . . . . 910

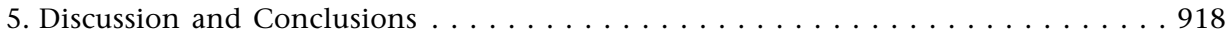

References............................... 920

Introduction and transformations of organic functional groups to ten- and twelve-vertex closo-boranes and heteroboranes is reviewed in the context of preparation of liquid crystalline compounds. The review, containing 198 references, is designed as a synthetic manual for materials chemists and focuses on methods for engineering molecules with elongated shapes and variable dipole moments. Several underdeveloped aspects of closo-borane chemistry are identified.

Key words: Boranes; Carboranes; Heteroboranes; Clusters; Liquid crystals.

\section{INTRODUCTION}

The synthesis of the first organic derivatives of closo-dodecaborate (1, Fig. 1) and closo-decaborate 7 in 1962 (ref. ${ }^{1}$ ) followed by a number of organic derivatives of ortho-carborane $\mathbf{4}$ (refs ${ }^{2,3}$ ) and meta-carborane 5 (ref. ${ }^{4}$ ), signaled the beginning of an exciting period for closo-borane chemistry and applications of inorganic-organic hybrid materials ${ }^{5}$. High chemical, thermal and electrochemical stability of the ten- and, especially, twelve-vertex closo- 
boranes $^{6}$ (Fig. 1) have been utilized in preparation of thermostable polymers $^{7}$. The low toxicity ${ }^{8}$ of closo-borates $\mathbf{1}$ and $\mathbf{7}$ makes them suitable for biomedical applications such as boron neutron capture therapy ${ }^{9,10}$. More recently, boron clusters have been used as non-nucleophilic anions ${ }^{11}$ and for molecular materials such as molecular-scale construction sets ${ }^{12-14}$. Exploration of boron clusters as structural elements for liquid crystals is the most recent chapter in the chemistry and application of closo-boranes ${ }^{15}$. So far only several of the ten clusters, decaborate 7 (refs ${ }^{16,17}$ ), monocarbaborate $\mathbf{2}$ (ref. ${ }^{18}$ ), and para-carboranes $\mathbf{6}$ and $\mathbf{1 0}$ (refs $^{17,19-23}$ ), have been used in the synthesis of liquid crystals. The results obtained to date ${ }^{15}$ demonstrate the structural versatility of these compounds and their enormous potential in the study of the phenomenon and applications of liquid crystals.

The rich chemistry of the clusters in Fig. 1 and the understanding of their properties has been driven by scientific curiosity and materials demands and described in several reviews $s^{6,24-31}$. Here we will concentrate on the transformations of closo-boranes that lead to disubstitution in the antipodal position giving electrically neutral molecules with the most extended molecular shapes which are prerequisite for liquid crystalline behavior ${ }^{15}$.

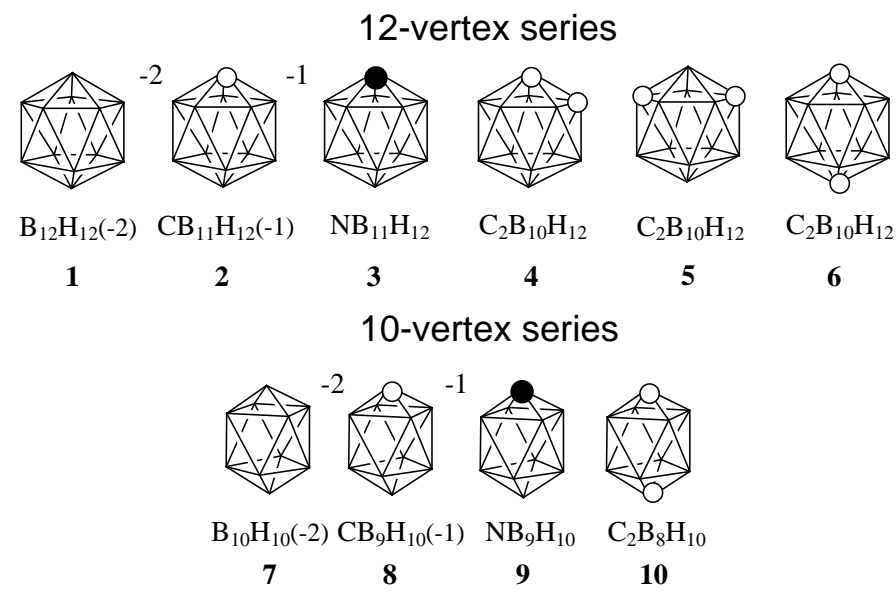

FIG. 1

Skeletal representations of the borates $(\mathbf{1}, \mathbf{7})$, monocarbaborates $(\mathbf{2}, \mathbf{8})$, azaboranes $(\mathbf{3}, \mathbf{9})$, ortho-carborane (4), meta-carborane (5), and para-carboranes $(\mathbf{6}, \mathbf{1 0})$ shown with chemical formulas. In the structures each vertex corresponds to a B-H fragment and the $\mathrm{CH}$ and $\mathrm{NH}$ groups are marked by open and filled circles, respectively 


\section{PREPARATION OF THE PARENT CLUSTERS}

Commercially available decaborane(14) (11) is the common precursor to all ten clusters 1-10 as shown in Scheme 1. Generally the twelve-vertex closo-clusters are more convenient to prepare than the ten-vertex analogs. For the former, insertion reactions are typically used, while the synthesis of the ten-vertex clusters involves selective degradation processes of the eleven- and twelve-vertex species.

The transformation of $\left[\mathrm{B}_{10} \mathrm{H}_{14}\right](\mathbf{1 1})$ to the anions $\mathbf{1}$ (ref. ${ }^{32}$ ) and $\mathbf{7}$ (ref. ${ }^{33}$ ) were the first syntheses of the closo-skeleton which involved borane insertion $^{34}$ or amine-induced dehydrogenation ${ }^{35}$ reactions, respectively.

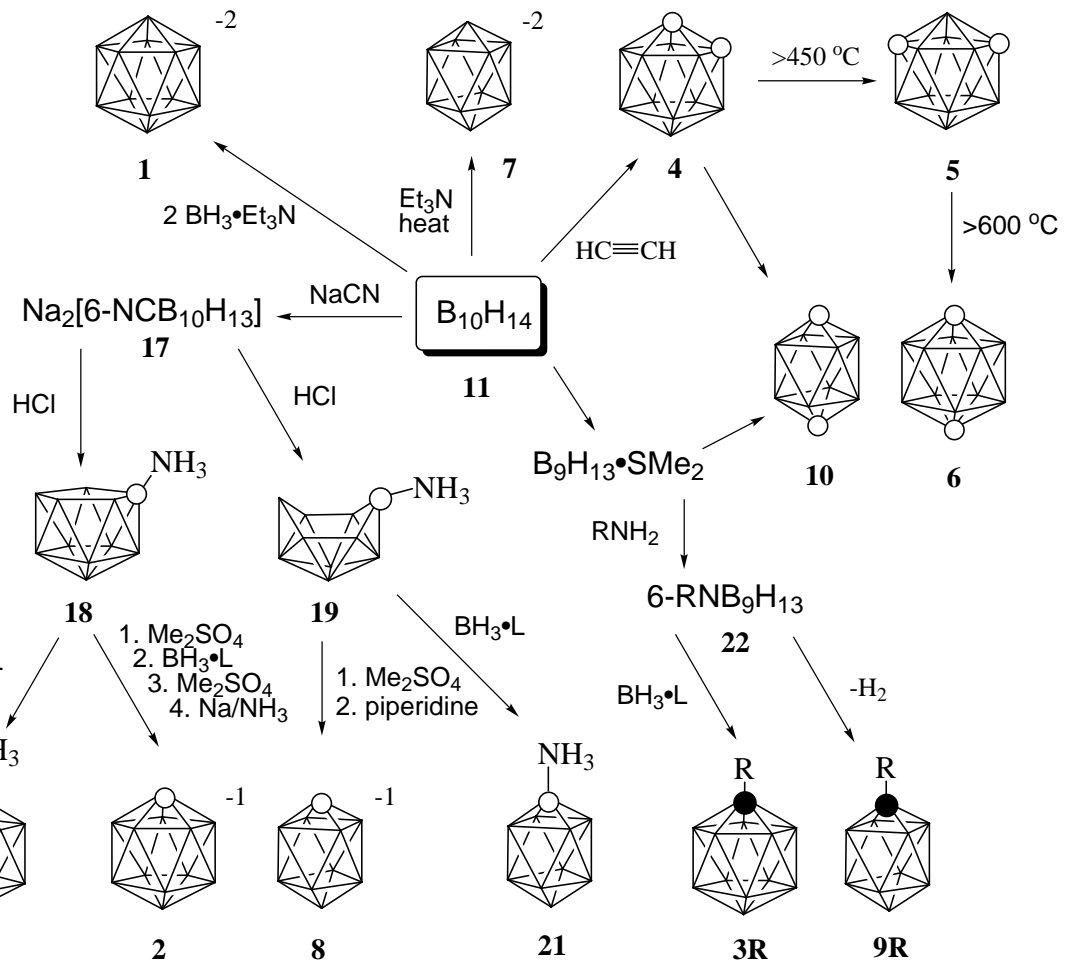

SCHEME 1

The twelve-vertex ortho-carborane 4 (ref. ${ }^{2}$ ) has been obtained by acetylene insertion to decaborane $\mathbf{1 1}$ (refs ${ }^{36,37}$ ). Reaction of substituted acetylenes provides a convenient route to mono- and disubstituted derivatives of $\mathbf{4}\left(\right.$ refs $\left.^{2,38,39}\right)$. 
Thermolysis of ortho-carborane 4 at $465-500{ }^{\circ} \mathrm{C}$ (ref. ${ }^{4}$ ) or in a flow system at $600{ }^{\circ} \mathrm{C}$ (ref. ${ }^{40}$ ) produces the meta isomer 5 in high yield ${ }^{4}$, while higher temperatures give an equilibrium mixture of para-carborane $\mathbf{6}$ and its meta isomer. The para isomer 6 (ref. ${ }^{41}$ ) can be separated chromatographically ${ }^{42}$, taking advantage of the difference in the polarity ${ }^{43}(2.85 \mathrm{D}$ for 5$)$ or by selective conversion of the meta isomer to the $\left[\mathrm{C}_{2} \mathrm{~B}_{9} \mathrm{H}_{12}\right]^{-}$nido anion (12, Scheme 2$)^{44}$. This latter method is particularly convenient for large-scale preparations of $\mathbf{6}$.

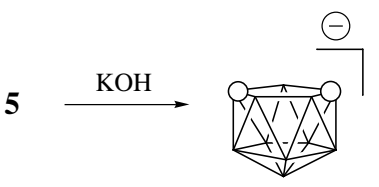

12

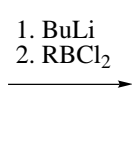

13

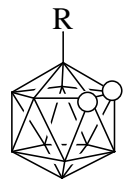

14

SCHEME 2

Some C-substituted meta-carboranes, but not para-carboranes, have been obtained by thermal rearrangement of the corresponding C-substituted ortho-carboranes. This method is limited to methyl ${ }^{4}$, ethyl ${ }^{45}$, and phenyl ${ }^{46}$ derivatives while other alkyls ${ }^{45}$ and functional groups ${ }^{4}$ show limited thermal stability.

2-Substituted meta-carboranes $\mathbf{1 3}$ have been efficiently prepared either by $\mathrm{RBCl}_{2}\left(\mathrm{R}=\mathrm{Ph}\left(\right.\right.$ ref. $\left.{ }^{47}\right), \mathrm{R}=\mathrm{C}_{6} \mathrm{H}_{4}-4-\mathrm{Me}\left(\right.$ ref. $\left.{ }^{47}\right), \mathrm{R}=\mathrm{C}_{6} \mathrm{H}_{4}-4-\mathrm{F}$ (ref. ${ }^{47}$ ), $\mathrm{R}=$ vinyl $\left(\right.$ refs $\left.^{28,49}\right)$, and $\mathrm{R}=\mathrm{F}\left(\right.$ ref. $\left.^{50}\right)$ ) insertion reaction into the nido anion $\mathbf{1 2}$ or skeletal rearrangement of 3-substituted ortho-carboranes 14. Flash vacuum thermal rearrangement of 3-CN, 3- $\mathrm{NH}_{2}, 3-\mathrm{OH}$, and 3-F (ref. ${ }^{50}$ ) derivatives of ortho-carboranes $\mathbf{1 4}$ gives good yields of equimolar mixtures of the 2- and 4-substituted meta-carboranes, which can be separated using chromatographic methods ${ }^{50,51}$.

Ten-vertex para-carborane $\mathrm{e}^{52} \mathbf{1 0}$ has been obtained in a similar way to its twelve-vertex analog $\mathbf{6}$ by thermal rearrangement of the corresponding ortho-carborane 15a via the meta isomer at the relatively low temperatures of $330-350{ }^{\circ} \mathrm{C}$ (Scheme 3$)^{52}$. The ortho-carborane 15a is prepared by ther$\mathrm{mal}^{53}$ or base-induced dehydrogenation ${ }^{54,55}$ of nido-carborane 16 a obtained either through sequential deboronation ${ }^{54,56}$ of twelve-vertex ortho-carborane 4 or by acetylene insertion ${ }^{57}$ to $\mathrm{B}_{9} \mathrm{H}_{13}\left(\mathrm{SMe}_{2}\right)$. The overall yield of para-carborane $\mathbf{1 0}$ is 30-50\% based on the starting ortho-carborane 4.

Preparation of C-substituted para-carboranes generally follows the preparation of the parent carborane $\mathbf{1 0}$ and it takes advantage of the relatively 
Iow skeletal rearrangement temperatures tolerated by some organic substituents ${ }^{58}$. Thus, thermal isomerization of C-methyl ${ }^{52,59}, \mathrm{C}$-pentyl ${ }^{58}$, C-hexyl ${ }^{58}, \mathrm{C}$-phenyl ${ }^{52}, \mathrm{C}-\left(\mathrm{C}_{6} \mathrm{H}_{4}-4-\mathrm{Br}\right.$ ) (ref. ${ }^{58}$ ), and $\mathrm{C}-\left(\mathrm{C}_{6} \mathrm{H}_{4}-4-\mathrm{F}\right.$ ) (ref. ${ }^{60}$ ) ten-vertex closo-carboranes has been reported to form the corresponding para isomers in high yields at $350{ }^{\circ} \mathrm{C}$. The main difference between the preparation of the parent carborane $\mathbf{1 0}$ and its derivatives lies in the generally low yield for the second deboronation reaction ${ }^{56,58}$ but the lower volatility of the substituted carboranes simplifies the thermolysis step ${ }^{58}$.

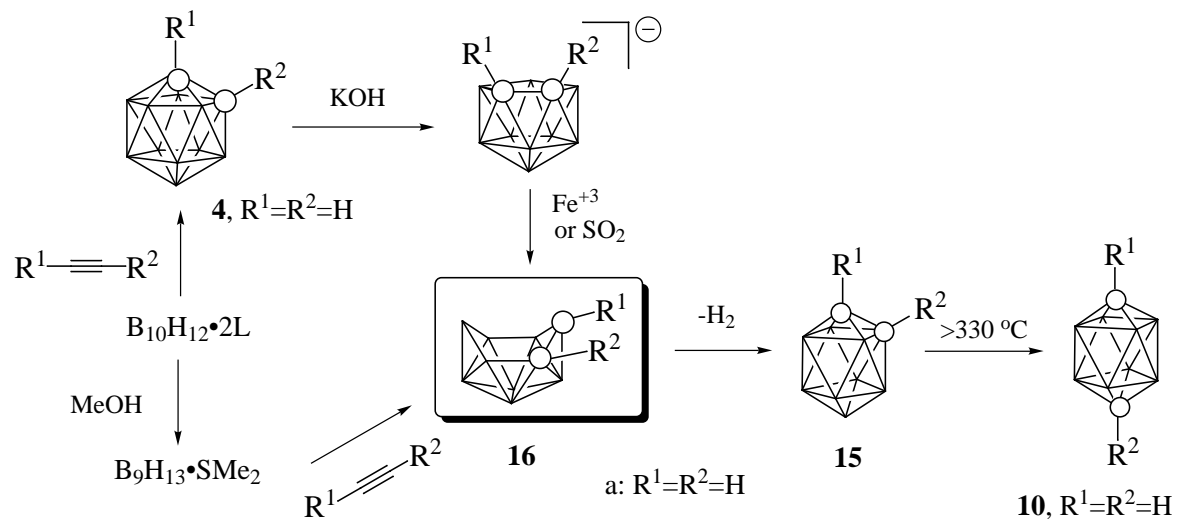

SCHEME 3

Monocarbaborate anions $\mathbf{2}$ and $\mathbf{8}$ were prepared relatively early ${ }^{61,62}$ and several reviews on their chemistry and properties have recently appeared $^{11,28,31}$. The carbon atom is introduced as a nitrile ligand to form arachno adduct $\mathbf{1 7}$ (Scheme 1), which, upon hydrolysis and partial degradation with $\mathrm{HCl}$, yields a mixture of nido amines [7- $\left.\mathrm{NH}_{3}-\mathrm{CB}_{10} \mathrm{H}_{12}\right]$ (18) and [6- $\mathrm{NH}_{3} \mathrm{CB}_{9} \mathrm{H}_{11}$ ] (19) in proportions dependent upon the reaction conditions $^{63-65}$. N-M ethylation followed by dehydrogenation-deamination of the latter using piperidine yields $\mathbf{8}$ (ref.66), while $\mathbf{1 8}$ requires borane insertion and sodium metal cleavage of the [1-NM $\mathrm{N}_{3}-\mathrm{CB}_{11} \mathrm{H}_{11}$ ] to furnish 2 (ref. ${ }^{65}$ ).

C-Amino substituted monocarbaboranes $\mathbf{2 0}$ and $\mathbf{2 1}$ have been obtained in good yields via borane insertion to [7- $\mathrm{NH}_{3}-\mathrm{CB}_{10} \mathrm{H}_{12}$ ] (18) (ref. ${ }^{67}$ ) and borane-induced dehydrogenation of $\left[6-\mathrm{NH}_{3}-\mathrm{CB}_{9} \mathrm{H}_{11}\right]$ (19) (ref. ${ }^{68}$ ), respectively. Borane insertion reactions to [7-SMe $2-\mathrm{CB}_{10} \mathrm{H}_{12}$ ] (ref. ${ }^{67}$ ) or [7- $\mathrm{NMe}_{3}-\mathrm{CB}_{10} \mathrm{H}_{12}$ ] (ref. ${ }^{65}$ ) result in demethylation and products [1-SMe-CB $\left.\mathrm{B}_{11} \mathrm{H}_{11}\right]^{-}$and [1-NMe $\left.\mathrm{N}_{2}-\mathrm{CB}_{11} \mathrm{H}_{11}\right]^{-}$, respectively, have been obtained. The latter is also obtained in $61 \%$ yield in the cage expansion reaction of $\left[1-\mathrm{NM}_{3}-\mathrm{CB}_{9} \mathrm{H}_{9}\right.$ ] with borane ${ }^{68}$. 
The newest addition to the pool of closo-heteraboranes are the aza boranes ${ }^{69}$. Unlike the synthesis of 9 (ref. $\left.{ }^{70}\right)$, the preparation of the parent $\left[\mathrm{NB}_{11} \mathrm{H}_{12}\right]$ (3) is rather inefficient and involves the dangerous hydrazoic acid $^{71}$. N-Substituted derivatives are easily prepared using the corresponding amines and $\left[\mathrm{B}_{9} \mathrm{H}_{13}\left(\mathrm{SM} \mathrm{e}_{2}\right)\right]$ via the nido derivative 22 (Scheme 1) ${ }^{69}$. Subsequent thermal dehydrogenation of $\mathbf{2 2}$ yields ten-vertex derivatives $\mathbf{9 R}$ (ref. ${ }^{72}$ ) whereas borane insertion to $\mathbf{2 2}$ leads to the corresponding $\mathbf{3 R}$ derivatives $^{73,74}$.

\section{FUNCTIONALIZATION OF THE TEN- AND TWELVE-VERTEX CLUSTERS}

Over the last 35 years the chemistry of all ten boron clusters 1-10 has been well advanced and methods for substitution at the boron, carbon, and nitrogen sites have been developed. Among the clusters, the twelve-vertex carboranes 4-6 and borates $\mathbf{1}$ and $\mathbf{7}$ are the most studied, largely due to their availability. Least investigated are monocarbaborate $\mathbf{8}$ and the recently prepared azaboranes $\mathbf{3}$ and $\mathbf{9}$, which are less readly available due to more complicated syntheses.

The hydrogen atoms on the endoskeletal carbon and nitrogen atoms in 2-6 and 8-10 exhibit protic character (e.g., $\mathrm{pK}_{a}=26.8$ for 6 and 27.3 for 10) ${ }^{75}$. They can easily be removed using alkyllithiums ${ }^{25}$, LDA (ref. ${ }^{13}$ ), and t-BuOK (refs ${ }^{13,76}$ ) giving rise to highly nucleophilic heteroanions (C-anions or $\mathrm{N}$-anions). The skeletal $\mathrm{B}-\mathrm{H}$ groups undergo electrophilic substitution reactions with a variety of electrophiles with the preference for the antipodal position to the heteroatom.

In principle, substitution and chemical transformations of the boron, carbon, and nitrogen centers are transferable between the clusters and between the ten- and twelve-vertex series, although differences in reactivity and regiochemistry are occasionally observed. For instance, carbon chemistry developed for ortho- and meta-carboranes and described in previous reviews ${ }^{25,27}$ is applicable to the less available para-carboranes $\mathbf{6}$ and $\mathbf{1 0}$ and, to a large extent, to monocarbaborates $\mathbf{2}$ and $\mathbf{8}$. On the other hand, stable dinitrogen derivatives are unique to decaborate $\mathbf{7}$ although several clusters undergo synthetically useful diazotization-substitution reactions (vide infra).

From the liquid crystal point of view, substituents such as $n$-alkyl, n-alkoxyl, n-alkylthio, cycloalkyl and aryl and functional groups such as esters, nitriles, Schiff bases and azo groups are particularly useful structural elements ${ }^{77-79}$. Judicious choice of these groups allows for modulation and tuning of thermal, optical and dielectric properties of the materials. Here we will concentrate on synthetic methods that allow for introduction of 
these substituents onto the boron cluster. The chemistry of azaboranes will be omitted in the following discussion. Although azaboranes $\mathbf{3}$ and $\mathbf{9}$ can be $\mathrm{N}$-alkylated ${ }^{80}$ and $\mathrm{B}$-halogenated ${ }^{81}$ they exhibit rather significant sensitivity to solvents and nucleophiles ${ }^{69}$ and their usefulness for materials purposes is questionable $\mathrm{e}^{74}$.

\subsection{Carbon Substitution}

Carbon-carbon bonds. Carborane and monocarbaborate-derived anions are highly nucleophilic and react with a wide range of $\mathrm{C}$-electrophiles providing a convenient route to $\mathrm{C}-\mathrm{C}$ bonds. The $\mathrm{C}$-lithium reagents are particularly useful in the alkylation with primary iodides and bromides and carboxylation reactions described for carboranes including para-carboranes $\mathbf{6}$ (refs $^{20,82,83}$ ) and $\mathbf{1 0}$ (refs $^{58,84,85}$ ), and also for monocarbaborates $\mathbf{2}$ (refs $^{67,86}$ ) and $\mathbf{8}$ (ref. ${ }^{61}$ ). The preparation of 12-pentyl-para-carborane-1-carboxylic acid (23, Scheme 4) is an example of both processes ${ }^{20,82}$. It also demonstrates our recently developed strategy for efficient differentiation of the two carbon atoms in 6 using a $\mathrm{Ph}_{3} \mathrm{Si}$ substituent, which induces crystallinity and UV activity facilitating isolation, purification and storage of the products and intermediates ${ }^{82}$. Other methods for heterodisubstitution in $\mathbf{6}$ (refs $\left.{ }^{87,88}\right), \mathbf{1 0}$ (ref. $^{12}$ ), and $\mathbf{4}$ (refs ${ }^{89,90}$ ) are less general.
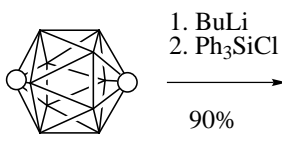

6

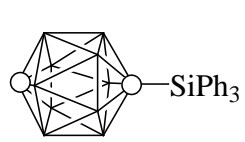

1. $\mathrm{BuLi}$

2. $\mathrm{C}_{5} \mathrm{H}_{11} \mathrm{Br}$

$92 \%$

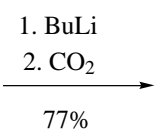

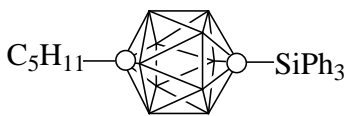

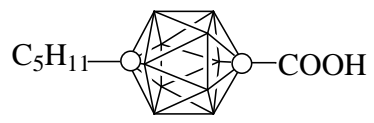

23

SCHEME 4

Carboranylcopper reagents $\mathbf{2 4}$ provide excellent means for the preparation of C-aryl 25, C-vinyl $\mathbf{2 6}$ (ref. ${ }^{91}$ ), and C-acetylene $\mathbf{2 7}$ (refs ${ }^{23,82,91}$ ) derivatives (Scheme 5). Unlike the carboranyllithiums, the carboranylcopper reagents do not equilibrate with the $\mathrm{C}-\mathrm{H}$ acid form and high degrees up to $80 \%$ of monoarylation of 6 have been obtained ${ }^{13,82,92}$. The original Wade procedure $^{76}$ for arylation of the twelve-vertex carboranes ${ }^{13,82,92,93}$ has been extended to arylation ${ }^{58,94}$ and ethynylation ${ }^{23}$ of the ten-vertex para-carborane 10. Attempts to use the procedure for the introduction of perfluoroalkyl de- 
rivatives proved unsuccessful, and only carboranyl halides $\mathbf{2 8}$ (bromides and iodides) were obtained in the metal-halogen exchange process (Scheme 5) ${ }^{82}$. A similar metal-halogen exchange reaction is also observed with some acetylene iodides and bromides.

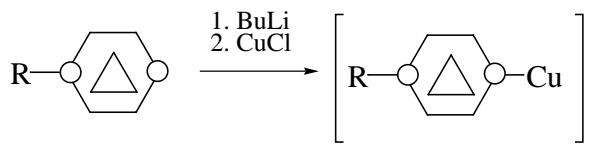

24
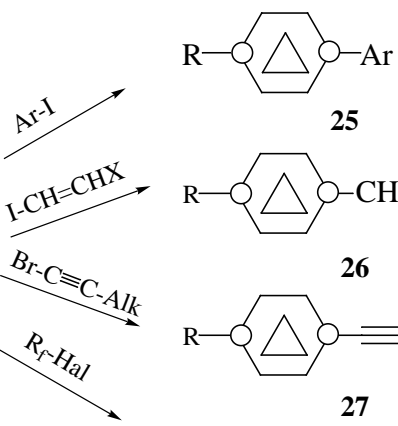

25

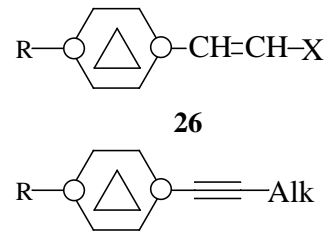

27

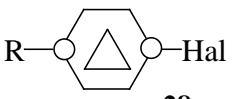

28

It appears that carboranylcoper species are the only effective reagents in arylation reactions. Ten-vertex carboranylzinc is the only exception found so far, and it reacts with 4'-cyano-4-biphenyl triflate under the Negishi reaction conditions, giving a modest yield of the coupling product $\mathbf{2 9}$ (ref. ${ }^{95}$ ). The analogous $\mathrm{Pd}$-catalyzed coupling reactions of twelve-vertex para-carboranylzinc ${ }^{96}$ or stannan $e^{13}$ with iodobenzene or with aryl triflates were unsuccessful and no coupling product was observed.
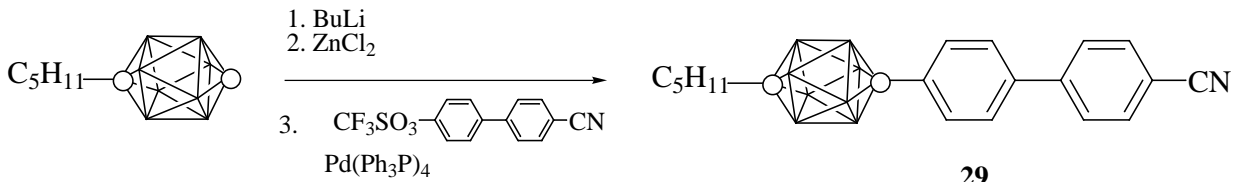

29

Among other carbon electrophiles that react with carboranyl anions are PhOCN, preferred for preparation of the ten-vertex para-carborane nitriles ${ }^{97}$, and tosyl cyanide, the reagent of choice for synthesis of twelvevertex carboranenitriles ${ }^{98}$.

The reaction of orthoformates with ten-97 or twelve-vertex ${ }^{88,99}$ carboranyllithium yields carboranyl acetals which are easily converted to the corresponding aldehydes. For instance, para-carborane-1,12-dicarb- 
aldehyde was obtained in 23\% overall yield based on para-carborane 6 (ref. ${ }^{99}$ ). The reaction of para-carborane $\mathbf{6}$ under controlled conditions gives a non-statistical yield of acetal $\mathbf{3 0}$, which is converted to 12 -hydroxypara-carborane-1-carbaldehyde (31) via boronic acid 32 (Scheme 6) ${ }^{88}$.

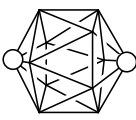

6

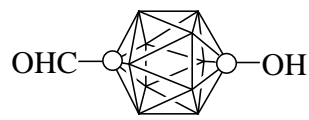

31

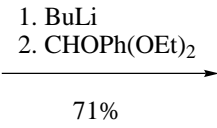

$71 \%$

$\mathrm{AcOOH}$

SCHEME 6

A special case of the $\mathrm{C}-\mathrm{C}$ bond formation is the dimerization reaction of para-carborane. Oxidative coupling of either ten-12,84 or twelvevertex ${ }^{12,100,101}$ carboranyllithium with anhydrous $\mathrm{CuCl}_{2}$ gives a high yield of the desired dimeric product 33. If more than one equivalent of BuLi is used then higher oligomers are formed ${ }^{12,101 .}$

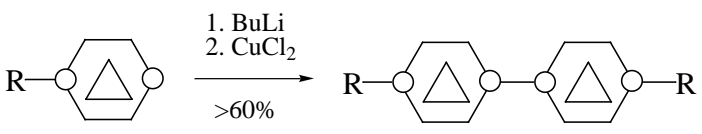

33

Carbon-nitrogen bonds. There are relatively few examples of $\mathrm{C}-\mathrm{N}$ bond formation. Direct amination of dilithio-para-carborane with MeONHLi has been reported to give a mixture of the 1-amino- and 1,12-diamino-paracarboranes ${ }^{87}$. Attempts to extend this procedure to $\left[12-\left(n-C_{7} \mathrm{H}_{15}\right)-1-\mathrm{Li}-\mathrm{CB}_{11} \mathrm{H}_{10}\right]$ resulted in only traces of the desired 1 -amino product ${ }^{94}$.

An alternative approach to the desired C-amino carboranes utilizes the acid-catalyzed cleavage of triazines that can be obtained from carboranyllithium and phenylazide in about $80 \%$ yield ${ }^{102}$.

C-Nitrosylation of para-carboranyllithium with $\mathrm{NOCl}$ was reported to proceed in about $30 \%$ yield ${ }^{103}$. C-Nitrosylation of monosubstituted orthoand meta-carboranyllithium occurs in good yield and meta-carboranyllithium can be dinitrosylated in 30\% yield ${ }^{104,105}$. Attempted C-nitrosylation of [12-(n- $\left.\left.\mathrm{C}_{7} \mathrm{H}_{15}\right)-1-\mathrm{Li}-\mathrm{CB}_{11} \mathrm{H}_{10}\right]$ was unsuccessful ${ }^{94}$. 
Reactions of ortho- or meta-carboranyllithium with a benzenediazonium salt yield the corresponding azo derivatives such as 34, which exhibit remarkably high thermal and chemical stability ${ }^{106,107 .}$
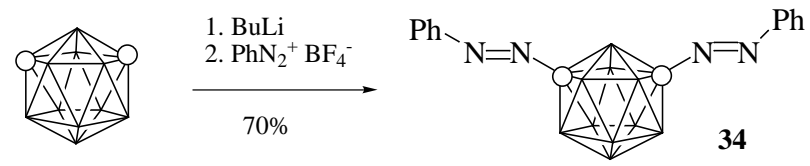

Catalytic reduction of azocarboranes ${ }^{107}$ is a recommended method for the preparation of $\mathrm{C}$-amino derivatives and is preferable to the reduction of C-nitroso ${ }^{104}$ or C-nitro ${ }^{85}$ compounds.

Carbon-sulfur bonds. Formation of the $\mathrm{C}-\mathrm{S}$ bond can be effected by treatment of the C-lithium or C-sodium derivatives of ortho-carborane 4 (refs $\left.{ }^{89,108-111}\right)$, meta-carborane $\mathbf{5}$ (refs ${ }^{108,109,111}$ ), para-carborane $\mathbf{6}$ $\left(\right.$ refs $^{82,103,109,111,112}$ ) and monocarbaborate $\mathbf{2}$ (ref. ${ }^{67}$ ) with elemental sulfur $67,89,103,108-112$, sulfur dioxide ${ }^{103,108}$, dialkyl disulfide ${ }^{110}$, or alkylsulfenyl halides ${ }^{82}$ as shown for 35.
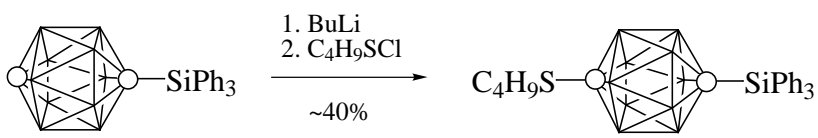

35

The C-S bond has rather limited stability. Lithium salts of the carboranethiols in benzene and aqueous carboranesulfinic acids undergo thermal desulfurization above $50{ }^{\circ} \mathrm{C}$ (ref. ${ }^{108}$ ). Alkylthio derivatives such as 35 undergo partial decomposition on silica ${ }^{82}$ and are susceptible to attack and cleavage by alkyllithiums ${ }^{110}$ and fluoride anion ${ }^{82}$. 1-Alkylthioortho-carboranes, however, have been reacted with BuLi and converted into the corresponding C-anions in high yields ${ }^{113}$.

Carbon-oxygen bonds. Direct C-oxygenation has been accomplished by reacting carboranyllithium with oxygen ${ }^{114}$ or peroxides ${ }^{115}$ among which trimethylsilyl peroxide was found to work best, giving yields of the C-hydroxy-para-carborane up to $30 \%$ (refs $^{88,116}$ ). An even more efficient method for introduction of the hydroxy group through the oxidation of the corresponding C-boronic acid was reported recently (Scheme 6) ${ }^{88}$. The sequence of reactions starting from $\mathbf{3 0}$ gives 12-hydroxy-para-carborane1-carbaldehyde (31), a carborane analog of 4-hydroxybenzal dehyde, in $88 \%$ of overall yield. 
Carbon-halogen bonds. There are relatively few examples of the formation of $\mathrm{C}$-halogen bonds. The $\mathrm{C}$-halogenation reaction is highly efficient ${ }^{85,103,117}$ and occasionally observed as an undesired processes (vide supra). The C-I compounds have limited synthetic utility (vide infra) ${ }^{118}$ while the $\mathrm{C}-\mathrm{F}$ and $\mathrm{C}-\mathrm{Cl}$ compounds may be used to increase molecular dipole moments ${ }^{119}$ and to introduce axial chirality in 2,9-disubstituted meta-carboranes. All C-halogen derivatives are susceptible to base-induced dehalogenation.

Carbon-mercury bonds. Reaction of ten- or twelve-vertex para-carboranyl anion with mercury(II) halide leads to the formation of a stable dicarboranylmercury, e.g. 36, with an extended molecular shape ${ }^{13,103,120}$. The anion has been generated using alkyllithiums ${ }^{120}$ or LDA (ref. ${ }^{13}$ ) and reacted with mercury halide or formed in situ with potassium tert-butoxide in DMF in the presence of $\mathrm{HgBr}_{2}$ (ref. ${ }^{13}$ ).

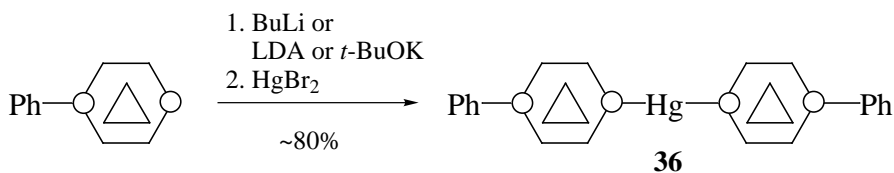

\subsection{Boron Substitution}

The regiochemistry of electrophilic substitution in boron clusters is frequently complicated by the presence of two or more types of boron atoms in the cage. Although one position in the cage typically has higher electron density and is thermodynamically preferred $(B(2)$ in 6 and 10, $B(9)$ in 4 and 5, $B(1)$ and $B(10)$ in $\mathbf{7}, B(10)$ in 8 and $\mathbf{9}, B(12)$ in 2 and $\mathbf{3})$, the substitution occasionally occurs at kinetic sites (vide infra). The regioselectivity of substitution depends on the cluster, type of el ectrophile, and, occasionally, reaction conditions.

There are two general types of electrophiles which react with a negatively charged cluster to yield either charged or electrically neutral products as shown for a monocarbaborate in Fig. 2.

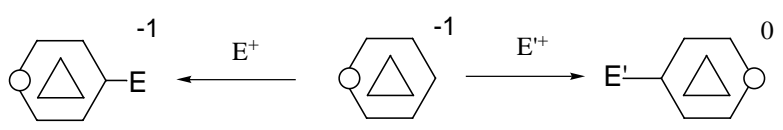

FIG. 2

Substitution with electrophiles $\mathrm{E}^{+}$or $\mathrm{E}^{+}$shown using the monocarbaborate as example 
Among the electrophilic reactions, iodination, diazotization, metallation, and sulfurization reactions provide particularly valuable and versatile intermediates in the context of synthesis of liquid crystals. Other reactions are much less selective or preferentially yield the undesired regioisomers.

Boron-iodine bonds. Iodination of the clusters typically proceeds in high yield and with high regioselectivity for the thermodynamic position. The reaction rate and the conditions depend on the type of the cluster; charged clusters undergo iodination under mild conditions while neutral boranes and, in particular para-carborane 6, require Lewis acids as catalysts. Monoiodination ${ }^{121,122}$ of 1-methyl- and 1-phenyl-ortho-carborane 123-125 $^{12}$ yields a mixture of 12- and 9-iodo derivatives, 37 and 38, respectively, from which the desired 12-iodo isomer 37 can be separated chromatographically ${ }^{124,125}$. Diiodination of para-carborane $\mathbf{6}$ proceeds in high yield but lacks selectivity and the desired 2,9-isomer 39 has been isolated in only $11 \%$ yield (Scheme 7$)^{126}$.
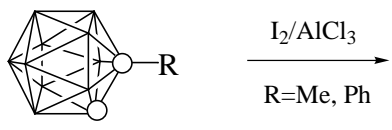

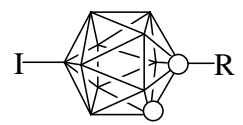

37

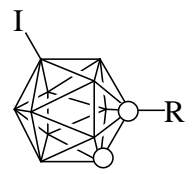

38

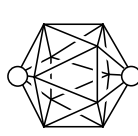

6
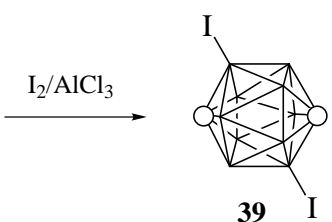

$+\quad$ other isomers

SCHEME 7

Iodination of twelve-vertex monocarbaborate anion $\mathbf{2}$ proceeds in a high yield and is highly selective for the 12 -position ${ }^{67}$. Similarly, iodination of quinuclidine derivative $\mathbf{4 0}$ with $\mathrm{ICl}$ predominantly yields the 12 -iodo derivative $\mathbf{4 1}$ in 40 or $73 \%$ yield based on recovered starting material ${ }^{127}$. Iodination of the 1- $\mathrm{NMe}_{3}$ analog with $\mathrm{I}_{2}$ and $\mathrm{AlCl}_{3}$ as the catalyst was reported to give $81 \%$ yield of the corresponding 12 -iodo product ${ }^{128}$.

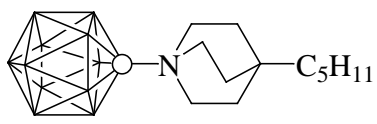

40

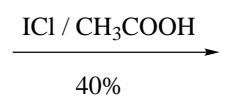

$40 \%$

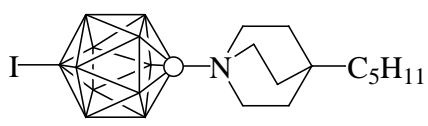

41 
Reaction of $\mathrm{I}_{2}$ with [1-NHMe $-\mathrm{CB}_{11} \mathrm{H}_{11}$ ] under basic conditions led to the $\mathrm{N}$-demethylation product ${ }^{129}$.

Iodination as well as other halogenation reactions of ten-vertex analog 8 exhibits high regioselectivity for the 6 position and the desired 10-iodo1-carba-closo-decaborate (42) is formed in less than $2 \%$ yield ${ }^{130}$. It has been proposed that the latter may be obtained by thermal rearrangement of the kinetic 6-isomer $\mathbf{4 3}$ isolated in $51 \%$ yield ${ }^{130}$.

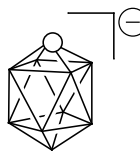

8

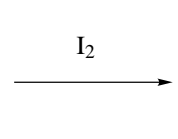

43

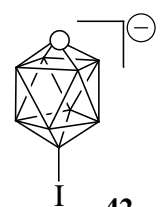

42

Boron-nitrogen bonds. The formation of stable dinitrogen inner salts is specific to the $\left[\mathrm{B}_{10} \mathrm{H}_{10}\right]^{2-}$ anion (7) and no other cluster has been reported to form such derivatives. Thus diazotization of $\mathbf{7}$ with nitrous acid followed by reductive workup yields about $15-25 \%$ of the 1,10-bis(dinitrogen)-closodecaborane (44) as the only product ${ }^{131}$. The uniquely high isomeric purity of the isolated $\mathbf{4 4}$ and other analogous compounds ${ }^{132,133}$ is not necessarily related to the high regioselectivity of the substitution. It is more likely that other isomers are formed but only the 1,10- isomer is stable enough to be isolated. Our ab initio calculations support this hypothesis showing that the apical $\mathrm{N}_{2}$ group is twice as stable to heterolytic cleavage than that in the equatorial position ${ }^{96}$.

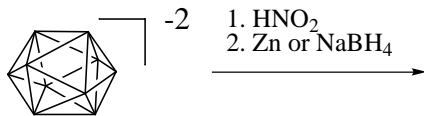

7

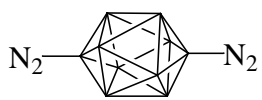

44

Reaction of the closo-decaborate anion (7) with one equivalent of arenediazonium salts to form azo compounds $\mathbf{4 5}$ is another example of a transformation unique to this cage and highly regiospecific for the apical position ${ }^{134,135}$. The observation that certain aryl groups eliminate under weakly basic conditions yielding the dinitrogen derivatives allowed for selective preparation of 1-dinitrogen-closo-decaborate (46) and differentiation of the apical position 136,137 . 


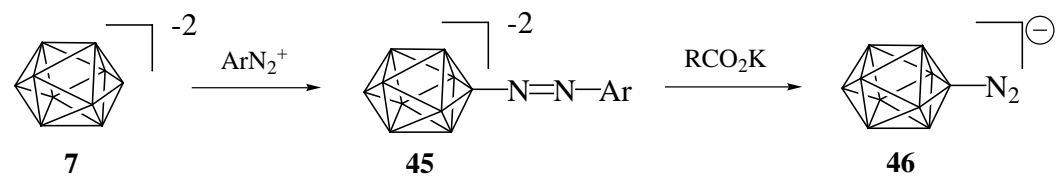

This method also permits the introduction of the dinitrogen to the substituted decaborate monoanions providing an invaluable tool for heterodisubstitution of $\mathbf{7}$ (vide infra) ${ }^{136}$. For instance, dinitrogen derivative $\mathbf{4 7}$ was obtained from the anion $\mathbf{4 8}$ in $>50 \%$ yield using the Hawthorne method ${ }^{136}$, while diazotization-reduction sequence of the Knoth method ${ }^{131,132}$ is only half as efficient ${ }^{16}$.

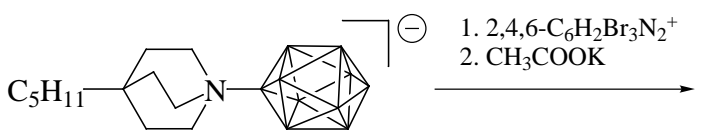

48

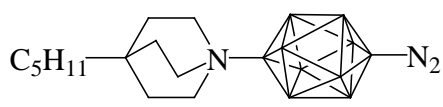

47

Direct electrophilic amination reactions of charged boranes yield the kinetic meta isomers as the major products and only traces of the desired para isomers are formed. Reaction of closo-dodecaborate anion $\mathbf{1}$ with hydroxylamine-0-sulfonic acid results in the formation of small quantities $(<10 \%)$ of the desired 1,12-diamine ${ }^{138,139}$, while the same reaction for the ten-vertex analog 7 yields equatorial diamines only 138 . Similar results are obtained for hydroxylation reactions with amides and sulfones ${ }^{140,141}$.

Amination of monocarbaborate $\mathbf{2}$ with hydroxylamine-0-sulfonic acid gives only traces of the desired 12-amino isomer and the meta isomer is the sole product in addition to the recovered starting $\mathbf{2}$ (ref. ${ }^{142}$ ).

Boron-metal bonds. Metallation of twelve-vertex boron closo-clusters with mercury or thallium trifluoroacetates occurs at the thermodynamic position with high selectivity 143,144. Parent and substituted carboranes $\mathbf{4}$ and $\mathbf{5}$ yield 9-metallo derivatives (e.g. 49) and para-carborane 6 gives the 2-metallo derivative in high yields ${ }^{145}$. Reduction of the resulting metallo derivatives leads to dicarboranylmercury (e.g. 50), typically obtained in high yields ${ }^{143,145}$. The regiosel ectivity of mercuration of C-monosubstituted carboranes has not been investigated ${ }^{145}$. 


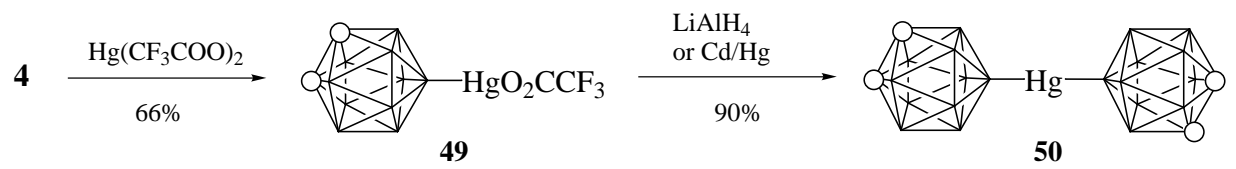

Mercuration of monocarbaborate 2 results in the 12-mercurio derivative obtained in $72 \%$ yield ${ }^{86}$ and its $1-\mathrm{NMe}_{3}$ derivative $\mathbf{5 1}$ was mercurated to form 52 in $37 \%$ yield ${ }^{146}$.

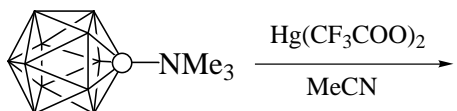

51

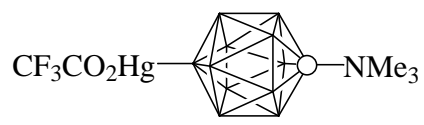

52

Mercuration of $\left[\mathrm{B}_{12} \mathrm{H}_{12}\right]^{2-}$ gives high yields of dimercurio derivatives, the regiochemistry of which has not been established ${ }^{147}$.

Boron-sulfur bonds. 9-Mercaptocarboranes of ortho- and meta-carboranes have been obtained by direct sulfhydrylation with elemental sulfur in the presence of $\mathrm{AlCl}_{3}$ catalyst in good to excellent yields ${ }^{109,148,149}$. Alternatively, the thiols have been prepared by reaction of carboranes with $\mathrm{S}_{2} \mathrm{Cl}_{2}$ in the presence of $\mathrm{AlCl}_{3}$, followed by reduction with $\mathrm{Zn}$ dust and acid or $\mathrm{NaBH}_{4}$ (ref. ${ }^{150}$ ).

Reaction of monocarbaborate $\mathbf{2}$ with dimethyl sulfoxide (DMSO) under acidic conditions leads to the neutral 12-dimethylsulfido derivative isolated in $44 \%$ yield along with $23 \%$ of a byproduct arising from a DMSO self-condensation reaction ${ }^{67}$. Extending this procedure to cyclic sulfoxide 53 gives about $20 \%$ yield of the desired product 54 (ref. ${ }^{151}$ ).

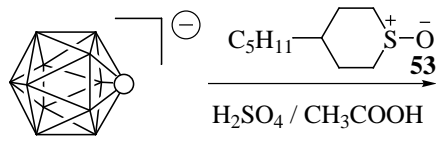

2

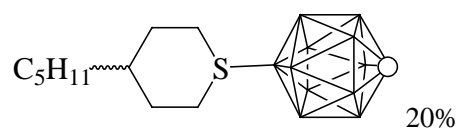

54

A similar reaction of closo-decaborate 7 with DMSO in the presence of $\mathrm{HCl}$ yields mixtures of apical and equatorial products ${ }^{133,152}$. Electrophilic sulfurization of closo-dodecaborate 1 with DMSO (ref. ${ }^{153}$ ) or (SCN) 2 (ref. ${ }^{154}$ ) results in the almost exclusive formation of the 1,7-isomers, although a small amount of $\left[1,12-(\mathrm{SCN})_{2}-\mathrm{B}_{12} \mathrm{H}_{10}\right]^{2-}$ has been isolated ${ }^{154}$. 
Other el ements bonded to boron. Although B-chloro and B-fluoro derivatives are too unreactive to be useful intermediates in Pd-catalyzed coupling reactions, they can be used to modify the molecular dipole moments ${ }^{155,156}$ and break the symmetry introducing axial chirality.

A high-pressure carbonylation reaction of the dodecaborate anion $\mathbf{1}$ gives the highest selectivity among the substitution reactions for the desired 1,12- isomer and dicarbonyl compound 55 was obtained in $40 \%$ yield ${ }^{157}$. Unfortunately, the difficult reaction conditions needed to form this compound hinder its broader use as the starting material for preparation of other 1,12-disubstituted derivatives of $\mathbf{1}$.

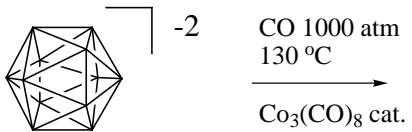

1

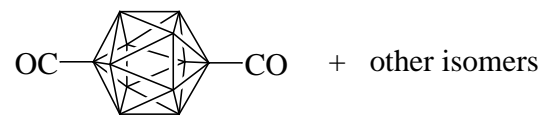

$5540 \%$

Reactions of $\left[\mathrm{B}_{12} \mathrm{H}_{12}\right]^{2-}$ with other electrophiles proceed with the formation of predominately meta $(1,7-)$ isomers and the desired para $(1,12-)$ isomers are minor products which are difficult to detect and isolate ${ }^{132,140,153}$. Similarly, other electrophilic substitution reactions of $\left[\mathrm{B}_{10} \mathrm{H}_{10}\right]^{2-}$ yield either mixtures of apical/equatorial or exclusively equatorial ${ }^{6}$ products: e.g. reaction with halogens ${ }^{158}$, carbonyl chlorides ${ }^{132,140,158,159}$, protonated MeCN (ref. ${ }^{160}$ ), and $\mathrm{N}, \mathrm{N}$-dimethylthioformamide ${ }^{152}$.

\section{FUNCTIONAL GROUP TRANSFORMATIONS}

Several classes of closo-borane derivatives are particularly important intermediates in synthesis of liquid crystalline materials. Among them are carboxylic acids, which are precursors to esters, amines, and nitriles. B-Iodo derivatives are key intermediates to introduce alkyl, aryl, and acetylene groups. Amines and dinitrogen derivatives of borates $\mathbf{1}$ and $\mathbf{7}$ are particularly useful for introduction of onium substituents such as pyridinium and sulfonium. Alkylation and alkylation-cyclization of hydroxy, mercapto, and amino derivatives of boranes are convenient ways to introduce a flexible chain or to build a ring into the molecular rigid core.

Derivatives of closo-boranecarboxylic acids. Formation of esters from carboranecarboxylic acids is typically accomplished in high yield by using carboxylic acid chlorides and an alcohol or phenol in the presence of pyridine or $\mathrm{Et}_{3} \mathrm{~N}$ (Scheme 8$)^{17,19,20}$. The chlorides of either $\mathrm{C}$ - or 
B-carboxylic acids ${ }^{48,49}$ are prepared by using $\mathrm{PCl}_{5}$, which is superior to other reagents.

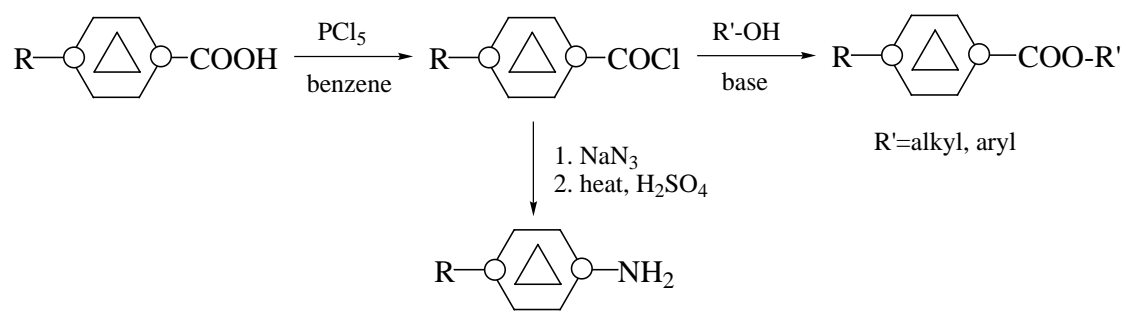

\section{SCHEME 8}

Carboxylic acids and their anhydride forms (e.g. 55) have been used for the synthesis of amines. For instance, C- and B-carboranecarboxylic acids $^{48,49}$ and also carbonyl derivatives of $\mathbf{1}$ and $\mathbf{7}$ undergo a Schmidt-type reaction with $\mathrm{H}_{2} \mathrm{NOSO}_{3} \mathrm{H}$ in aqueous solution to yield the corresponding amines ${ }^{132,157}$. A Curtius-type reaction of acid chlorides or anhydrides with $\mathrm{NaN}_{3}$ leads to the corresponding amines $87,103,157,161,162$ via intermediate isocyanates (Scheme 8) 157,162.

Dehydration of carboxamides, conveniently prepared by ammonolysis of carbonyl chlorides ${ }^{25}$, with trimethylsilyl polyphosphate ${ }^{163}$ provides a high yield route to carboranylnitriles (e.g. 56) ${ }^{96}$.

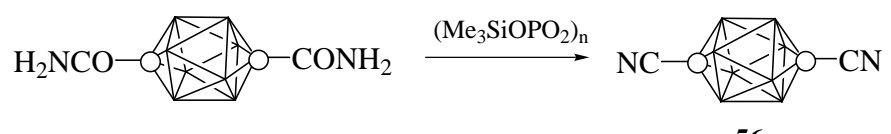

56

Acid hydrolysis of B-cyanocarboranes furnishes the corresponding carboxylic acids and provides an alternative route to this class of compounds ${ }^{51}$.

C-Carboranecarbaldehydes such as $\mathbf{5 7}$ are susceptible to amine-induced cleavage of the $\mathrm{C}-\mathrm{C}$ bond as well as cage deboronation (e.g. butylamine). Only the less basic aromatic amines (e.g. aniline) were successfully reacted to form the corresponding Schiff base $\mathbf{5 8}$ in good yields ${ }^{164}$.

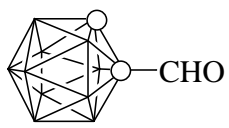

57

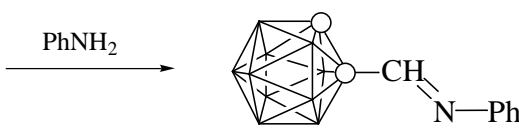

58 
Aldehydes, e.g. $\mathbf{5 7}$ are most reliably prepared from the corresponding hydroxymethyl derivatives using the Swern oxidation reaction ${ }^{165}$. The hydroxymethyls are typically obtained from reaction of carboranyllithiums and formaldehyde ${ }^{166}$.
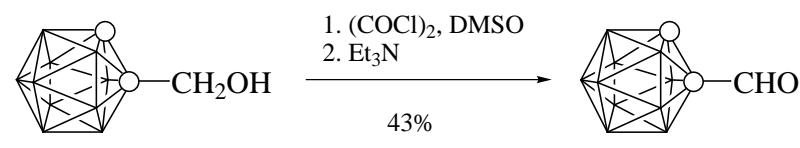

57

Baeyer-Villiger oxidation of closo-borane ketones has not been investigated in detail except in the case of derivatives of $\left[\mathrm{B}_{12} \mathrm{H}_{12}\right]^{2-}$ and $\left[\mathrm{B}_{10} \mathrm{H}_{10}\right]^{-}$, which provide access to the corresponding B-hydroxy derivatives ${ }^{132,140}$. Other routes to the B-hydroxy compounds include hydrolysis of amide and sulfone adducts to $\mathbf{1}$ and $\mathbf{7}$ (ref. ${ }^{141}$ ).

All carborane C-carbonyl compounds including esters ${ }^{166,167}$, alde hydes $^{99,168}$, and ketones ${ }^{169}$ are susceptible to nucleophile-induced cleavage but are stable under acidic conditions. For the carboranes, the rate of alkaline deformylation follows the order ortho $>$ meta $>$ para ${ }^{168}$. It was demonstrated, however, that basic hydrolysis of ethyl ortho-carborane-1-carboxylate gives excellent yield of the corresponding acid ${ }^{170}$.

Iodo-closo-boranes. A photochemical insertion of [1.1.1]propellane to the C-I bond of 1-iodo-para-carborane (59) to form 60 is a very elegant, and so far the only synthetic application of carborane $\mathrm{C}-\mathrm{I}$ derivatives ${ }^{118}$. The resulting iodobicyclo[1.1.1]pentane derivative $\mathbf{6 0}$ was dimerized to form the corresponding [2]staffane derivative in $75 \%$ yield ${ }^{118}$.

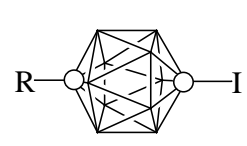

59

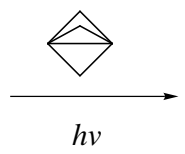

$h v$

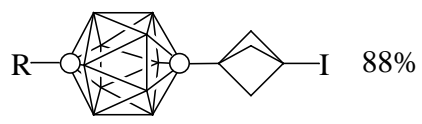

60

B-lodo compounds undergo Pd-catalyzed cross-coupling reactions with alkyl $^{171-176}$, aryl $123,126,139,173-178$ (e.g. 37) ${ }^{123}$ hetaryl $^{177}$, and acetylenyl ${ }^{126,174,179}$ (e.g. 39) ${ }^{126}$ organometallic reagents. First demonstrated for iodocarboranes ${ }^{175}$, the reaction has also been applied to charged species derived from $\left[\mathrm{B}_{12} \mathrm{H}_{11}\right]^{2-}$ (1) (refs $\left.{ }^{139,176}\right),\left[\mathrm{CB}_{11} \mathrm{H}_{11}\right]^{-}$(2) (ref. ${ }^{180}$ ), and neutral compounds such as ortho-carborane 4 (refs ${ }^{123,171,173-175,177,178}$ ), meta-carborane $\mathbf{5}$ (refs $^{173-175,177,178}$ ), and para-carborane 6 (refs ${ }^{126,175,179}$ ). More recently we have used it to transform $\mathbf{4 1}$ to $\mathbf{6 1}$ (Scheme 9) ${ }^{18}$. 

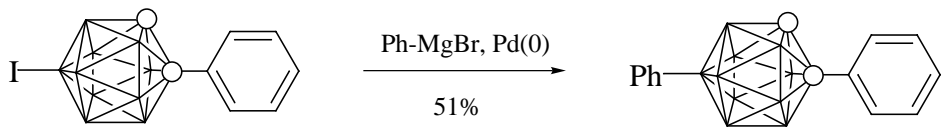

$37(\mathrm{R}=\mathrm{Ph})$
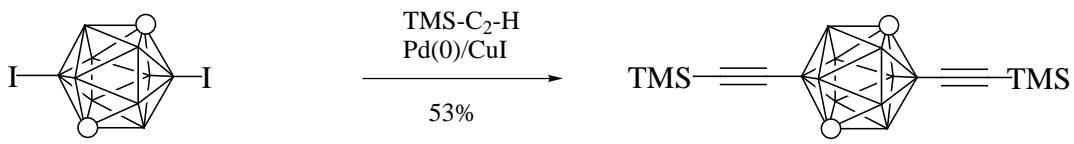

39

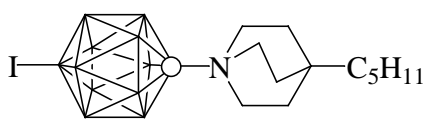

41

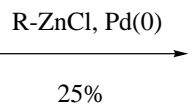

$25 \%$

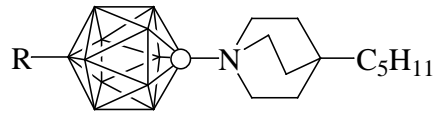

$61 \mathrm{R}=\mathrm{C}_{5} \mathrm{H}_{11}, \mathrm{C}_{10} \mathrm{H}_{21}$

SCHEME 9

Several types of organometallic compounds, including organic derivatives of $\mathrm{Mg}$ (refs ${ }^{123,126,171-173,175-178}$ ), Zn (refs ${ }^{18,174,181}$ ), and B (ref. ${ }^{182}$ ) have been used and the choice of the metal depends on the iodide structure and the type of organic residue. It was found that in coupling reactions 9-iodo-ortho-carborane is more reactive than the meta isomer ${ }^{177}$, organozinc reagents are most reactive in the cross-coupling reactions ${ }^{18,174}$, and the reactivity of Grignard reagents can be improved using benzene as the co-solvent ${ }^{177}$. Cross-coupling reactions of boronic acids with B-iodocarboranes under Suzuki conditions are in efficient giving a large fraction of byproducts ${ }^{182} . \operatorname{Pd}(0)$ catalysts have been found to be more effective than $\mathrm{Ni}(0)$ complexes, and the use of Cul as co-catalyst has a beneficial effect on the reaction ${ }^{126,173,180}$.

lodide $\mathbf{4 1}$ was found to react slowly with alkylzinc reagents in the presence of $\left(\mathrm{PPh}_{3}\right)_{4} \mathrm{Pd}$ and it proved resistant to all coupling reactions performed under other conditions ${ }^{94}$. Palladium-catalyzed coupling with either arylboronic esters, alkynes or $\mathrm{CuCN}$ failed ${ }^{94}$.

B-lodocarboranes are largely unreactive towards copper-mediated coupling reactions and substitution with thiolate anions ${ }^{183}$. 9-lodo-orthocarborane was converted, however, to the corresponding 9-cyano derivative using $\mathrm{CuCN}$ under forcing conditions $\mathrm{s}^{184}$ and it dimerized with copper powder to form 62 (ref. ${ }^{185}$ ).

Carboranyl iodides and other B-halides can be activated towards nucleophilic displacement by converting them into the corresponding 

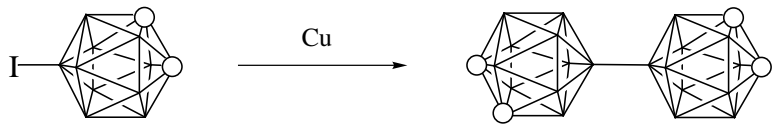

62

arylcarboranylhalonium salts e.g. 63 (refs ${ }^{186,187}$ ). The reaction has been demonstrated for ortho-, meta-, and para-carboranes and a variety of nucleophiles, and constitutes one the best ways to functionalize the $B(9)$ position in these clusters. The yields are in the range of $11-100 \%$ depending on the cluster, halide, aryl substituent, nucleophile and the reaction conditions ${ }^{186}$.

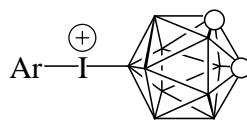

63

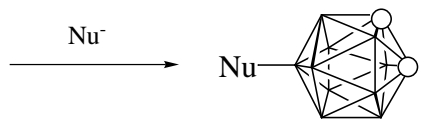

$\mathrm{Nu}=\mathrm{F}^{-}, \mathrm{CN}^{-}, \mathrm{SCN}^{-}, \mathrm{N}_{3}^{-}, \mathrm{OH}^{-}, \mathrm{RCO}_{2}^{-}$

Amino-closo-boranes. Boranamines are rather weak nucleophiles and their trialkylation requires either a strong el ectrophile or dipolar aprotic reaction conditions. Generally, alkylation-cyclization of ten-vertex boranamines is easier than that of their twelve-vertex analogs. For instance, amine $\mathbf{6 4}$ and diamine 65 were alkylated with tribromide 66 in MeCN and in the presence of $\mathrm{Me}_{4} \mathrm{NOH} \cdot 5 \mathrm{H}_{2} \mathrm{O}$ as the base to yield the corresponding 4-pentylquinuclidines 48 and 67, respectively (Scheme 10) ${ }^{16}$. Similar alkylation of 20

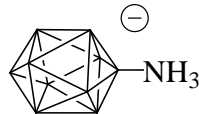

64

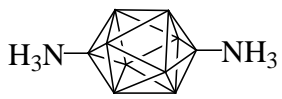

65

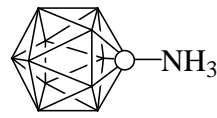

20

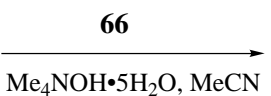

66

$\mathrm{Me}_{4} \mathrm{NOH} \cdot 5 \mathrm{H}_{2} \mathrm{O}, \mathrm{MeCN}$

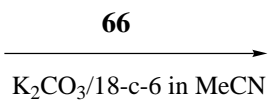

66:

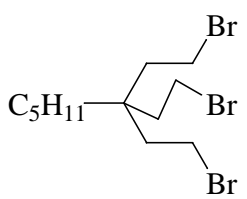

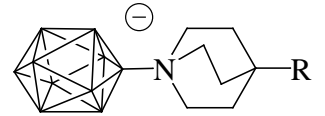

$>90 \%$

48

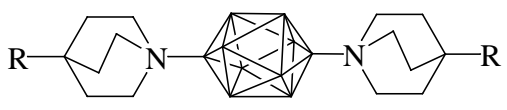

67

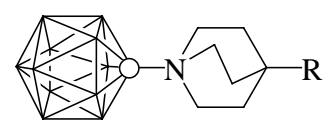

$29 \%$

SCHEME 10 
with $\mathbf{6 6}$ under the same conditions gave largely $\mathrm{HBr}$ elimination products, while using $\mathrm{K}_{2} \mathrm{CO}_{3} / 18$-crown- 6 in $\mathrm{MeCN}$ allowed isolation of $29 \%$ of the quinuclidine $\mathbf{4 1}$ (ref. ${ }^{127}$ ).

C-Amino and B-amino groups provide a convenient route to $\mathrm{C}-\mathrm{S}, \mathrm{C}-\mathrm{O}$, and $\mathrm{B}-\mathrm{F}$ derivatives by diazotization in the presence of the appropriate Lewis base. For instance, the diazotization reaction of 2-amino-metacarborane 68 in water yields 2-hydroxy-meta-carborane while the same reaction in liquid HF furnishes $83 \%$ of 2 -fluoro-meta-carborane $e^{48,49}$.

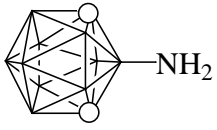

68

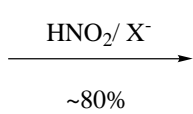

$\sim 80 \%$

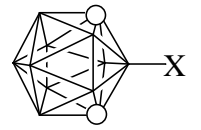

$\mathrm{X}=\mathrm{F}, \mathrm{OH}$

Diazotization of [1- $\mathrm{NH}_{3}-\mathrm{CB}_{11} \mathrm{H}_{11}$ ] (20) (ref. ${ }^{67}$ ) or 1-amino-ortho-carborane ${ }^{104}$ in the presence of water or acetic acid yields the corresponding C-hydroxy derivatives in $36 \%$ and $60 \%$ yield, respectively. Similarly, reaction of 20 (ref. ${ }^{67}$ ) or $\left[1-\mathrm{NH}_{3}-\mathrm{CB}_{9} \mathrm{H}_{9}\right]$ (21) (ref. ${ }^{68}$ ) in the presence of dimethyl sulfide furnishes the 1-dimethylsulfido derivatives in about $60 \%$ yield. Diazotization of [1- $\mathrm{NH}_{3}-\mathrm{CB}_{11} \mathrm{H}_{11}$ ] (20) in the presence of dimethylthioformamide as the nucleophile allowed for isolation of the corresponding sulfur derivative [1-(SCHNMe 2$\left.)-\mathrm{CB}_{11} \mathrm{H}_{11}\right]\left(\right.$ ref. $\left.^{151}\right)$.

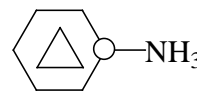

20, 21

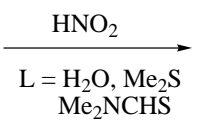

$\mathrm{Me}_{2} \mathrm{NCHS}$

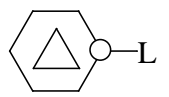

$50-70 \%$

Reaction of carboranylamines ${ }^{104}$ and 1-amino-closo-decaborate (64) 133,188 with benzaldehyde has been reported to produce the corresponding Schiff bases (e.g. 69) in high yields.
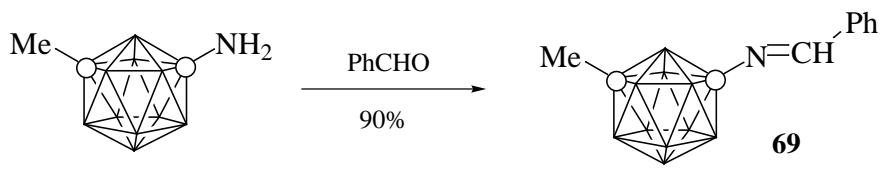

B-M etallated derivatives. B-M etallo derivatives of closo-boranes such as $\mathbf{7 0}$ react with a range of electrophiles under mild conditions, providing access to many important functional groups. Among them are iodides ${ }^{86,143}$ (from I $\mathrm{I}_{2}$ ), 
mercaptans ${ }^{189}$ (from $\mathrm{S}_{8}$ ), hydroxyls ${ }^{190}$ (from $\mathrm{CrO}_{3}$ ), and fluorides ${ }^{191}$ (from $\mathrm{BF}_{3} \cdot \mathrm{Et}_{2} \mathrm{O}$ ) obtained either from the mercurio or thallio derivatives.
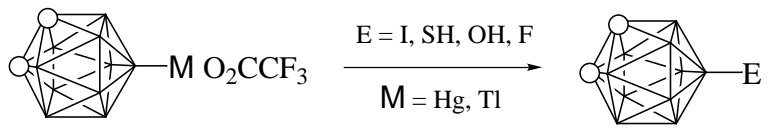

70

The B-mercurio derivatives photodissociate upon irradiation with UV light, and the resulting radicals react with arenes and olefins giving the corresponding B-substitution products in modest to good yields ${ }^{144}$.

Hydroxy-closo-boranes. The O-anions derived from highly acidic carboranyl $\mathrm{OH}$ groups ${ }^{115,116}$ are rather poor nucleophiles and they react well with strong alkylation reagents such as diazomethane $\mathrm{e}^{115}$, dimethylsulfate ([1- $\left.\left.(\mathrm{OH})_{2}-\mathrm{CB}_{11} \mathrm{H}_{11}\right]\right)$ (ref. $\left.{ }^{67}\right)$, and allyl iodide ${ }^{116}$. Acid chlorides ${ }^{115}$ and anhydrides ${ }^{48,51,192}$ convert the C-hydroxy ${ }^{115}$ and B-hydroxy $48,51,192$ compounds into corresponding esters in good yields.

An alkylation-cyclization and the formation of the pyran $\mathbf{7 1}$ in good yield has been demonstrated for the $\left[\mathrm{HO}-\mathrm{B}_{12} \mathrm{H}_{11}\right]^{2-}$ (ref. ${ }^{192}$ ).
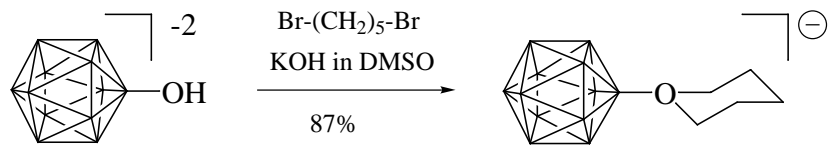

71

Mercapto-closo-boranes. S-Alkylation of either C-thiols ${ }^{108,113}$ or B-thiols $149,150,193,194$ is readily accomplished using moderately reactive electrophiles such as Mel (refs ${ }^{108,111,149,150,194}$ ) dimethyl sulfate $\left(\left[1-\left(\mathrm{SH}_{2}\right)-\mathrm{CB}_{11} \mathrm{H}_{11}\right]\right.$ (ref. $\left.{ }^{67}\right)$ and alkyl bromides ${ }^{113,193}$. Alkylation-cyclization of thiolates generated in situ by hydrolysis of thioformamide $\mathbf{7 2}$ with dibromide $\mathbf{7 3}$ gives the corresponding thiacyclohexane derivative $\mathbf{7 4}$ (ref. $\left.{ }^{16}\right)$.

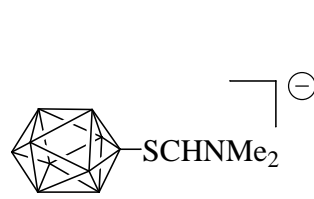

72

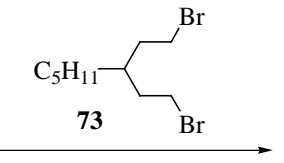

$\mathrm{Me}_{4} \mathrm{NOH} \cdot 5 \mathrm{H}_{2} \mathrm{O}$

(1)

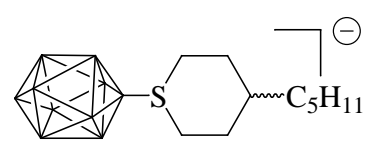

74 
Oxidation of alkylthio-149 and arylthiocarboranes ${ }^{150}$ with $\mathrm{H}_{2} \mathrm{O}_{2}-\mathrm{AcOH}$ gives the corresponding sulfoxides and sulfones in excellent yields.

Dinitrogen derivatives of decaborane. Dinitrogen derivatives $\mathbf{4 4}$ (ref. ${ }^{131}$ ) and 46 (ref. ${ }^{136}$ ) provide unique access to a variety of electrically neutral diapical homo- and heterodisubstituted [1- $\mathrm{LB}_{10} \mathrm{H}_{8}-10-\mathrm{L}^{\prime}$ ] (Scheme 11). Thermal decomposition of the dinitrogen derivatives at temperatures above $100{ }^{\circ} \mathrm{C}$ in neat Lewis bases such as substituted pyridine ${ }^{16,17}$, ammonia ${ }^{16,131}$, and $\mathrm{N}, \mathrm{N}$-dimethylthioformamide ${ }^{16,152}$, among others ${ }^{131-133}$ yields the substitution product. The reaction presumably proceeds through heterolytic cleavage of the $\mathrm{B}-\mathrm{N}$ bond and the resulting highly energetic intermediate reacts with the available nucleophile, even with benzene and cyclohexane ${ }^{131}$. Therefore the substitution reactions give good and very good yields only for small nucleophiles, but as the hydrocarbon substituents become dominant in the nucleophile molecule (e.g. 4-heptyloxypyridine) ${ }^{16,17}$, the yield diminishes.

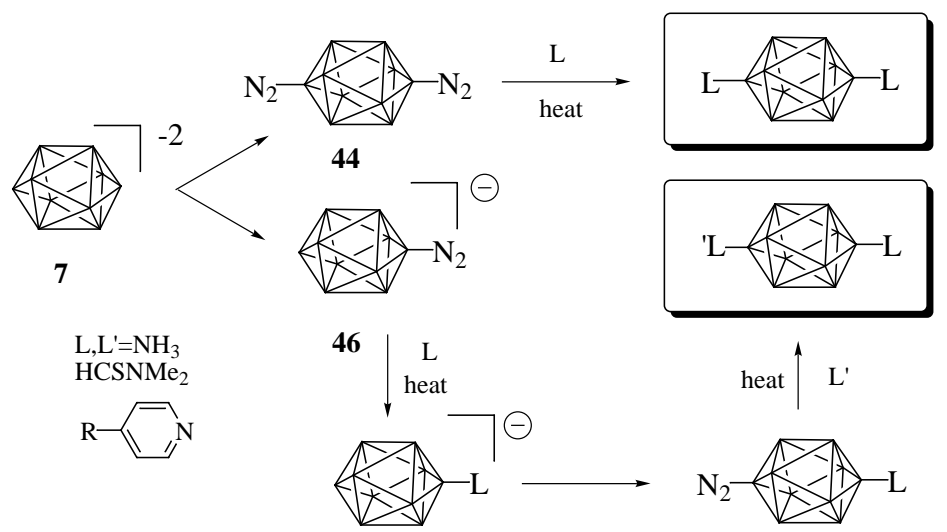

SCHEME 11

64,72

Examples of such syntheses are liquid crystals 75-77, obtained either in a one step process ${ }^{17}(\mathbf{7 5})$ or through sequential substitution ${ }^{16}(\mathbf{7 6}, \mathbf{7 7})$.

Other functional group transformations. Carboranes are relatively resistant to acids and some strong oxidizing reagents and many standard chemical transformations of the side chains and aromatic rings can be accomplished without affecting the carborane ring. It has been found that B-alkyl, -allyl, and -vinyl groups undergo oxidative degradation to form $\mathrm{B}-\mathrm{COOH}$ acids in high yields ${ }^{48,49,172,195}$. Functionalization of aromatic rings of arylcarboranes have been accomplished by acylation ${ }^{196}$, halogenation ${ }^{196}$, nitration $47,60,123,170,196-198$, 


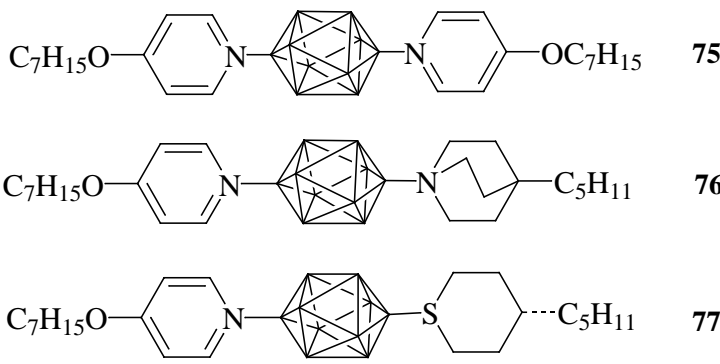

diazotization ${ }^{198}$, and oxidation reactions ${ }^{47}$. Phenol-substituted twelve-vertex carboranes have been obtained in good yields by pyridinium salt or $\mathrm{HI}$ cleavage of methyl aryl ethers ${ }^{92}$. Electrophilic substitution of the benzene ring preferentially occurs at the 4 position but typically mixtures of the para and meta isomers are obtained ${ }^{25}$.

We have demonstrated the Pd-catalyzed Suzuki coupling reaction of bromide 78 ( refs $^{21,96,151)}$.

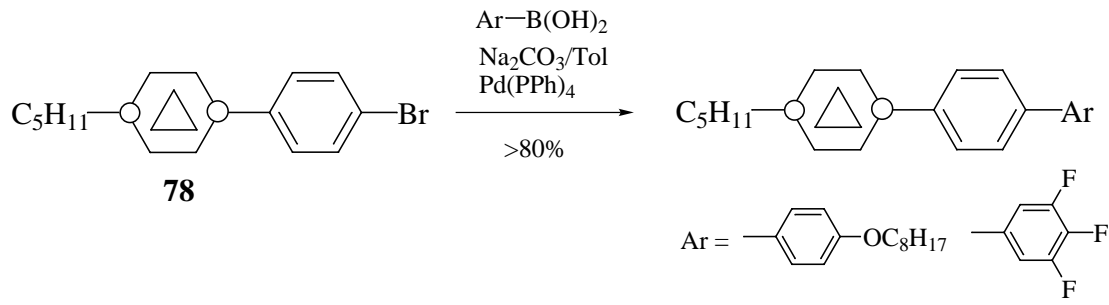

\section{DISCUSSION AND CONCLUSIONS}

At first glance, the geometry of closo-boranes resembles that of bicyclo[2.2.2]octane (BCO): both antipodally disubstituted derivatives have cylindrical rotational symmetry ${ }^{17}$. The BCO ring is considered an important structural element in synthesis of liquid crystal compounds from both fundamental and practical points of view. Most theories of liquid crystal phases assume molecules as cylindrical objects but in reality there are only very few such compounds except for some BCO derivatives. The use of BCO as structural element has also important practical benefits; incorporation of $\mathrm{BCO}$ into the molecular structure significantly enhances thermal stability of liquid crystal phases and promotes their nematogenic behavior.

The cylindrical symmetry of the $\mathrm{BCO}$ ring is rather rare among the organic rings. Of three such carbocycles ( $\mathrm{BCO}$, cubane, and bicyclo- 
[1.1.1]pentane) used as structural elements for liquid crystals, BCO is most synthetically available and, based on empirical data, most beneficial for properties. Unfortunately, the chemistry of the BCO ring is rather limited and the substituents must be "built in" during the ring construction (Fig. 3) ${ }^{77}$.

Ten- and twelve-vertex closo-boranes provide an alternative set of "cylindrical" structural elements with different stereochemical and electronic properties ${ }^{15}$. Study of a number and variety of such structurally similar liquid crystalline compounds is an important step towards better understanding the origin of liquid crystallinity. This, however, requires facile functionalization methodology for the rings and access to a variety of chemical structures. In contrast to $\mathrm{BCO}$, parent boron clusters undergo straightforward electrophilic or nucleophilic substitution reactions with typically high regioselectivity ensured by their unusual electronic structures. This also allows for introduction of an off-axis substituent $Z$ which will modify stereochemical and dipolar properties of the material. Very few substituents can be "built in" and $\mathbf{N H}_{2}$ in $\mathbf{2 0}$ and $\mathbf{2 1}$ is such an example (vide supra).

During the four decades of development of chemistry of closo-boranes and heteraboranes, an impressive number of organic functional groups have been introduced as substituents. Studies of their chemistry revealed that they undergo typical organic transformations and the clusters generally display reactivity typical of organic compounds rather than of boron hydrides. Further expansion of the "synthetic toolbox" for boron clusters and the availability of a large variety of disubstituted "cylinders" seems straightforward following standard organic-type transformations.

Boron clusters offer much more than an appriopriate shape for liquid crystals. Their conformational properties and electronic structures are unique among the ring structures and studies of their effects on liquid crystal behavior have only begun 22,23 . Full exploration of these effects will require, however, development of more synthetic and structural chemistry of

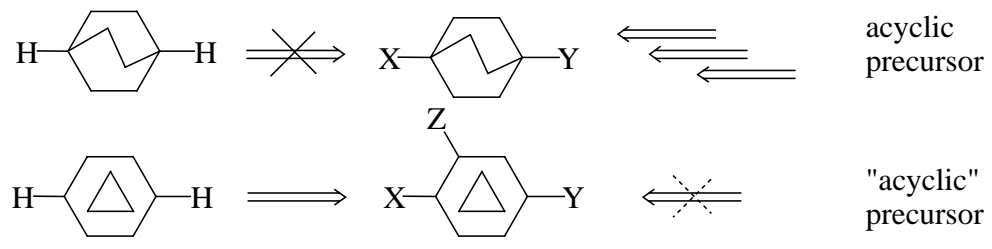

FIG. 3

Functionalization of bicyclo[2.2.2]octane (upper line) and closo-boranes (lower line) 
the clusters. For instance, methodology for regioselective $B(12)$ substitution of C-monosubstituted ortho-carboranes is almost nonexistent (vide supra) and $B(9)$ substitution of $B(2)$ derivatives of meta-carborane has never been reported. Such compounds would provide access to new liquid crystal structures with variable dipole moments. They could also be used to prepare axially dissymmetric derivatives, which are virtually unknown among the closo-boranes ${ }^{132}$. A combination of symmetry (or its lack) with the dipole moment is one of the most important issues in basic and applied science of liquid crystals.

Another unexplored area of closo-borane chemistry is the preparation and functionalization of the $\mathrm{B}(10)$ position in monocarbadecaborate (8). In addition, the methods for the preparation of 12-substituted monocarbaborate (2) and 1,12-disubstituted dodecaborate (1) derivatives are still unsatisfactory, and compound 55, currently the best precursor for the latter, is not readily available. All three types of derivatives would give structures with maximally elongated molecular shapes.

Although alkyl and alkylthio substituents have been introduced into boron clusters and their chemistry and stability studied, other groups such as alkoxy, alkylsulfinyl, and alkylsulfonyl are rare. Similarly, the properties of carborane-based azo compounds and Schiff bases is still awaiting more research. Extension of the cylindrical structure of the boranes with quinuclidine and bicyclo[1.1.1]pentane has been reported (vide supra) but coupling with a bridgehead iodide such as 1-iodobicyclo[2.2.2]octane has never been reported.

With time, these and other aspects of chemistry of closo-boranes will be addressed, bringing more synthetic tools for chemists to engineer new molecular and bulk materials.

Support for this project has been provided by the Petroleum Research Fund (PRF 28742), NSF CAREER grant (DMR-9703002), and the National Research Council under the Collaboration in Basic Science and Engineering Program (COBASE).

\section{REFERENCES}

1. Knoth W. H., Miller H. C., England D. C., Parshall G. W., Muetterties E. L.: J. Am. Chem. Soc. 1962, 84, 1056.

2. Heying T. L., Ager J. W., Jr., Clark S. L., Mangold D. J., Goldstein H. L., Hillman M., Polak R. J., Szymanski J. W.: Inorg. Chem. 1963, 2, 1089.

3. Zakharkin L. I., Stanko V. I., Brattstev V. A., Chapovskii Y. A., Struchkov Y. T.: Bull. Acad. Sci. U.S.S.R., Div. Chem. Sci. 1963, 1911.

4. Grafstein D., Dvorak J.: Inorg. Chem. 1963, 2, 1128. 
5. Plešek J.: Chem. Rev. 1992, 92, 269; and references cited therein.

6. Muetterties E. L., Knoth W. H.: Polyhedral Boranes. Dekker, New York 1968.

7. Williams R. E.: Pure Appl. Chem. 1972, 29, 569; and references therein.

8. Muetterties E. L., Balthis J. H., Chia Y. T., Knoth W. H., Miller H. C.: Inorg. Chem. 1964, 3, 444 .

9. Hawthorne M. F.: Angew. Chem., Int. Ed. Engl. 1993, 32, 950.

10. Soloway A. H., Tjarks W., Barnum B. A., Rong F.-G., Barth R. F., Codogni I. M., Wilson J. G.: Chem. Rev. 1998, 98, 1515.

11. Reed C.: Acc. Chem. Res. 1998, 31, 133.

12. Muller J., Baše K., Magnera T., Michl J.: J. Am. Chem. Soc. 1992, 114, 9721.

13. Schöberl U., Magnera T. F., Harrison R. M., Fleischer F., Pflug J. L., Schwab P. F. H., Meng X., Lipiak D., Noll B. C., Allured V. S., Rudalevige T., Lee S., Michl J.: J. Am. Chem. Soc. 1997, 119, 3907.

14. Hawthorne M. F., Mortimer M. D.: Chem. Brit. 1996, April, 33.

15. Kaszynski P., Douglass A. G.: J. Organomet. Chem. 1999, 581, 28.

16. Harvey J. E., Brady E., Kaszynski P., Young V. G., Jr.: Chem. Mater., submitted.

17. Kaszynski P., Huang J., Jenkins G. S., Bairamov K. A., Lipiak D.: Mol. Cryst. Liq. Cryst. 1995, 260, 315.

18. Douglass A. G., Pakhomov S., Kaszynski P.: submitted.

19. Douglass A. G., Czuprynski K., Mierzwa M., Kaszynski P.: Chem. Mater. 1998, 10, 2399.

20. Douglass A. G., Czuprynski K., Mierzwa M., Kaszynski P.: J. Mater. Chem. 1998, 8, 2391.

21. Czuprynski K., Douglass A. G., Kaszynski P., Drzewinski W.: Liq. Cryst. 1999, 26, 261.

22. Douglass A. G., Both B., Kaszynski P.: J. Mater. Chem. 1999, 9, 683.

23. Czuprynski K., Kaszynski P.: Liq. Cryst. 1999, 26, 775.

24. Hawthorne M. F. in: The Chemistry of Boron and Its Compounds (E. L. Muetterties, Ed.), p. 223. Wiley \& Sons, New York 1967.

25. Grimes R. N.: Carboranes. Academic Press, New York 1970; and references therein.

26. Middaugh R. L. in: Boron Hydride Chemistry (E. L. Muetterties, Ed.), p. 273. Academic Press, New York 1975.

27. Beall H. in: Ref. $^{26}$, p. 302.

28. Sivaev I. B., Kayumov A., Yakushev A. B., Solntsev K. A., Kuznetsov N. T.: Koord. Khim. 1989, 15, 1466.

29. Sivaev I. B., Solntsev K. A., Kuznetsov N. T.: Sov. J. Coord. Chem. 1991, 17, 470.

30. Bregadze V. I.: Chem. Rev. 1992, 92, 209.

31. Štíbr B.: Chem. Rev. 1992, 92, 225.

32. Pitochelli A. R., Hawthorne M. F.: J. Am. Chem. Soc. 1960, 82, 3228.

33. Hawthorne M. F., Pitochelli A. R.: J. Am. Chem. Soc. 1959, 81, 5519.

34. Miller H. C., Muetterties E. L.: Inorg. Synth. 1967, 10, 88.

35. Hawthorne M. F., Pilling R. L.: Inorg. Synth. 1966, 9, 16.

36. Hawthorne M. F., Andrews T. D., Garrett P. M., Olsen F. P., Reintjes M., Tebbe F. N., Warren L. F., Wegner P. A., Young D. C.: Inorg. Synth. 1967, 10, 91.

37. Kutal C. R., Owen D. A., Todd L. J.: Inorg. Synth. 1968, 11, 19.

38. Fein M. M., Grafstein D., Paustian J. E., Bobinski J., Lichstein B. M., Mayes N., Schwartz N. N., Cohen M. S.: Inorg. Chem. $1963,2,1115$.

39. Jiang W., Knobler C. B., Hawthorne M. F.: Inorg. Chem. 1996, 35, 3056.

40. Papetti S., Obenland C., Heying T. L.: Ind. Eng. Chem. Prod. Res. Dev. 1966, 5, 334.

41. Papetti S., Heying T. L.: J. Am. Chem. Soc. 1964, 86, 2295. 
42. Sieckhaus J. F., Semenuk N. S., Knowles T. A., Schroeder H.: Inorg. Chem. 1969, 8, 2452.

43. Laubengayer A. W., Rysz W. R.: Inorg. Chem. 1965, 4, 1513.

44. Janoušek Z.: Private communication.

45. Schoenfelder C. W., Fein M. M.: U.S. 1967, 3,355,496; Chem. Abstr. 1968, 68, P29859.

46. Hawthorne M. F., Young D. C., Garrett P. M., Owen D. A., Schwerin S. G., Tebbe F. N.,

Wegner P. A.: J. Am. Chem. Soc. 1968, 90, 862.

47. Zakharkin L. I., Kalinin V. N.: Russ. J. Gen. Chem. 1973, 43, 853.

48. Zakharkin L. I., Kalinin V. N., Gedymin V. V.: Russ. J. Gen. Chem. 1973, 43, 1956.

49. Zakharkin L. I., Kalinin V. N., Gedymin V. V.: Synth. React. Inorg. Met.-Org. Chem. 1973, 3, 93.

50. Roscoe J. S., Kongpricha S., Papetti S.: Inorg. Chem. 1970, 9, 1561.

51. Zakharkin L. I., Kalinin V. N., Kobelkova N. I.: Synth. React. Inorg. Met.-Org. Chem. 1976, 6, 91.

52. Garrett P. M., Smart J. C., Ditta G. S., Hawthorne M. F.: Inorg. Chem. 1969, 8, 1907.

53. Rietz R. R., Schaeffer R., Walter E.: J. Organomet. Chem. 1973, 63, 1.

54. Plešek J., Heřmánek S.: Collect. Czech. Chem. Commun. 1974, 39, 821.

55. Štíbr B., Plešek J., Heřmánek S.: Collect. Czech. Chem. Commun. 1973, 38, 338.

56. Štíbr B., Holub J., Jelínek T., Grüner B., Fusek J., Plzák Z., Teixidor F., Viñas C., Kennedy J. D.: Collect. Czech. Chem. Commun. 1997, 62, 1229.

57. Štíbr B., Teixidor F., Viñas C., Fusek J.: J. Organomet. Chem. 1998, 550, 125.

58. Janoušek Z., Kaszynski P.: submitted.

59. Tebbe F. N., Garrett P. M., Hawthorne M. F.: J. Am. Chem. Soc. 1968, 90, 869.

60. Zakharkin L. I., Kalinin V. N., Rys E. G., Kvasov B. A.: Bull. Acad. Sci. U.S.S.R., Div. Chem. Sci. 1972, 458.

61. Knoth W. H.: Inorg. Chem. 1971, 10, 598.

62. Knoth W. H.: J. Am. Chem. Soc. 1967, 89, 1274.

63. Baše K., Štíbr B., Dolanský J., Duben J.: Collect. Czech. Chem. Commun. 1981, 46, 2345.

64. Jelínek T., Štíbr B., Plešek J., Heřmánek S.: J. Organomet. Chem. 1986, 307, C13.

65. Plešek J., Jelínek T., Drdáková E., Heřmánek S., Štíbr B.: Collect. Czech. Chem. Commun. 1984, 49, 1559.

66. Nestor K., Štíbr B., Kennedy J. D., Thornton-Pett M., Jelínek T.: Collect. Czech. Chem. Commun. 1992, 57, 1262.

67. Jelínek T., Plešek J., Heřmánek S., Štíbr B.: Collect. Czech. Chem. Commun. 1986, 51, 819.

68. Jelínek T., Štíbr B., Plešek J., Thornton-Pett M., Kennedy J. D.: J. Chem. Soc., Dalton Trans. 1997, 4231.

69. Paetzold P.: Eur. J. Inorg. Chem. 1998, 143; and references therein.

70. Schneider L., Englert U., Paetzold P.: Z. Anorg. Allg. Chem. 1994, 620, 1191.

71. Muller J., Runsink J., Paetzold P.: Angew. Chem., Int. Ed. Engl. 1991, 30, 175.

72. Roth M., Paetzold P.: Chem. Ber. 1995, 128, 1221.

73. Lomme P., Meyer F., Englert U., Paetzold P.: Chem. Ber. 1995, 128, 1225.

74. Fendrich W., Harvey J. E., Kaszynski P.: Inorg. Chem. 1999, 38, 408.

75. Kruglyak L. I., Petrov E. S., Kalinin V. N., Rys E. G., Zakharkin L. I., Shatenshtein A. I.: Russ. J. Gen. Chem. 1972, 42, 2660.

76. Coult R., Fox M. A., Gill W. R., Herbertson P. L., McBride J. A. H., Wade K.: J. Organomet. Chem. 1993, 462, 19.

77. Collings P. J., Hird M.: Introduction to Liquid Crystals, Chemistry and Physics. Taylor \& Francis, Bristol 1997. 
78. Demus D. in: Handbook of Liquid Crystals (D. Demus, J. W. Goodby, G. W. Gray, H.-W. Spiess and V. Vill, Eds), Vol. 1, p. 133. Wiley, New York 1998.

79. Toyne K. J. in: Thermotropic Liquid Crystals (G. W. Gray, Ed.), p. 28. Wiley, New York 1987.

80. Meyer F., Muller J., Paetzold P., Boese R.: Angew. Chem., Int. Ed. Engl. 1992, 31, 1227.

81. Lomme P., Roth M., Englert U., Paetzold P.: Chem. Ber. 1996, 129, 1227.

82. Douglass A. G., Pakhomov S., Both B., Janoušek Z., Kaszynski P.: submitted.

83. Zakharkin L. I., Kalinin V. N., Podvisotskaya L. S.: Bull. Acad. Sci. U.S.S.R., Div. Chem. Sci. 1968, 2532.

84. Zakharkin L. I., Kovredov A. I.: Russ. J. Gen. Chem. 1974, 44, 1808.

85. Garrett P. M., Smart J. C., Hawthorne M. F.: J. Am. Chem. Soc. 1969, 91, 4707.

86. Jelínek T., Baldwin P., Scheidt W. R., Reed C. A.: Inorg. Chem. 1993, 32, 1982.

87. Kahl S. B., Kasar R. A.: J. Am. Chem. Soc. 1996, 118, 1223.

88. Malan C., Morin C.: Tetrahedron Lett. 1997, 38, 6599.

89. Viñas C., Benakki R., Teixidor F., Casabo J.: Inorg. Chem. 1995, 34, 3844.

90. Gomez F. A., Hawthorne M. F.: J. Org. Chem. 1992, 57, 1384.

91. Zakharkin L. I., Kovderov A. I., Olshevskaya V. A.: Bull. Acad. Sci. U.S.S.R., Div. Chem. Sci. 1986, 1260.

92. Fox M. A., MacBride J. A. H., Peace R. J., Wade K.: J. Chem. Soc., Dalton Trans. 1998, 401.

93. Gill W. R., Herbertson P. L., MacBride J. A. H., Wade K.: J. Organomet. Chem. 1996, 507, 249.

94. Douglass A. G., Kaszynski P.: Unpublished results.

95. Kaszynski P., Lipiak D. in: Materials for Optical Limiting (R. Crane, K. Lewis, E. V. Stryland and M. Khoshnevisan, Eds), Vol. 374, p. 341. MRS, Pittsburg 1995.

96. Kaszynski P.: Unpublished results.

97. Zakharkin L. I., Kalinin V. N., Rys E. G.: Russ. J. Gen. Chem. 1974, 44, 148.

98. Sung D. D., Jang J. A., Lim G. T., Shim S. C., Shim J. G., Antonova M. V., Kalinin V. N.: Mendeleev Commun. 1995, 26.

99. Zakharkin L. I., Kalinin V. N.: Synth. React. Inorg. Met.-Org. Chem. 1972, 2, 113.

100. Zakharkin L. I., Kovredov A. I.: Bull. Acad. Sci. U.S.S.R., Div. Chem. Sci. 1973, 1396.

101. Yang X., Jiang W., Knobler C. B., Hawthorne M. F.: J. Am. Chem. Soc. 1992, 114, 9719.

102. Polyakova L. A., Bilevich K. A., Bregadze V. I., Okhlobystin O. Y.: Bull. Acad. Sci. U.S.S.R., Div. Chem. Sci. 1972, 1846.

103. Zakharkin L. I., Kalinin V. N., Zhigareva G. G.: Bull. Acad. Sci. U.S.S.R., Div. Chem. Sci. 1970, 857.

104. Zakharkin L. I., Zhigareva G. G.: Russ. J. Gen. Chem. 1975, 45, 1268.

105. Kauffman J. M., Green J., Cohen M. S., Fein M. M., Cottrill E. L.: J. Am. Chem. Soc. 1964, 86, 4210 .

106. Kalinin V. N., Zhigareva G. G., Zakharkin L. I.: Synth. React. Inorg. Met.-Org. Chem. 1972, 2, 105.

107. Zakharkin L. I., Zhigarev G. G.: Bull. Acad. Sci. U.S.S.R., Div. Chem. Sci. 1989, 179.

108. Zakharkin L. I., Zhigareva G. G.: Russ. J. Gen. Chem. 1975, 45, 777.

109. Plešek J., Heřmánek S.: Collect. Czech. Chem. Commun. 1981, 46, 687.

110. Smith H. D., Jr., Obenland C. O., Papetti S.: Inorg. Chem. 1966, 5, 1013.

111. Zakharkin L. I., Zhigareva G. G.: Bull. Acad. Sci. U.S.S.R., Div. Chem. Sci. 1967, 1308.

112. Semenuk N. S., Papetti S., Schroeder H.: Inorg. Chem. 1969, 8, 2441. 
113. Teixidor F., Viñas C., Benakki R.: Inorg. Chem. 1997, 36, 1719.

114. Zakharkin L. I., Zhigareva G. G.: Russ. J. Gen. Chem. 1970, 40, 2318.

115. Zakharkin L. I., Zhigareva G. G.: Bull. Acad. Sci. U.S.S.R., Div. Chem. Sci. 1970, 2153.

116. Zharov I., Saxena A., Michl J., Miller R. D.: Inorg. Chem. 1997, 36, 6033.

117. Kongpricha S., Schroeder H.: Inorg. Chem. 1969, 8, 2449.

118. Mazal C., Paraskos A. J., Michl J.: J. Org. Chem. 1998, 63, 2116.

119. Echeistova A. I., Anorova G. A., Stanko V. I.: Russ. J. Struct. Chem. 1975, 16, 991.

120. Zakharkin L. I., Kalinin V. N., Rys E. G.: Russ. J. Gen. Chem. 1972, 43, 848.

121. Zakharkin L. I., Olshevskaya V. A., Poroshina T. Y., Balagurova E. V.: Russ. J. Gen. Chem. 1987, 57, 1800.

122. Andrews J. S., Zayas J., Jones M., Jr.: Inorg. Chem. 1985, 24, 3715.

123. Murphy D. M., Mingos D. M. P., Forward J. M.: J. Mater. Chem. 1993, 3, 67.

124. Zakharkin L. I., Kalinin V. N.: Dokl. Chem. Proc. Acad. Sci. U.S.S.R. 1966, 170, 832.

125. Zakharkin L. I., Kalinin V. N., Lozovskaya V. S.: Bull. Acad. Sci. U.S.S.R., Div. Chem. Sci. 1968, 1683.

126. Jiang W., Knobler C. B., Curtis C. E., Mortimer M. D., Hawthorne M. F.: Inorg. Chem. 1995, 34, 3491.

127. Douglass A. G., Janoušek Z., Kaszynski P., Young V. G., Jr.: Inorg. Chem. 1998, 37, 6361.

128. Morris J. H., Henderson K. W., Olshevskaya V. A.: J. Chem. Soc., Dalton Trans. 1998, 1951.

129. Plešek J., Jelínek T., Štíbr B.: Polyhedron 1984, 3, 1351.

130. Ivanov S. V., Rockwell J. J., Miller S. M., Anderson O. P., Solntsev K. A., Strauss S. H.: Inorg. Chem. 1996, 35, 7882.

131. Knoth W. H.: J. Am. Chem. Soc. 1966, 88, 935.

132. Hertler W. R., Knoth W. H., Muetterties E. L.: Inorg. Chem. 1965, 4, 288.

133. Knoth W. H., Hertler W. R., Muetterties E. L.: Inorg. Chem. 1965, 4, 280.

134. Hawthorne M. F., Olsen F. P.: J. Am. Chem. Soc. 1965, 87, 2366.

135. Zakharkin L. I., Pisareva I. V., Sulaimankulova D. D., Antonovich V. A.: Russ. J. Gen. Chem. 1990, 60, 2453.

136. Leyden R. N., Hawthorne M. F.: Inorg. Chem. 1975, 14, 2444.

137. Ng L.-L., Ng B. K., Shelly K., Knobler C. B., Hawthorne M. F.: Inorg. Chem. 1991, 30, 4278.

138. Hertler W. R., Raasch M. S.: J. Am. Chem. Soc. 1964, 86, 3661.

139. Grüner B., Bonnetot B., Mongeot H.: Collect. Czech. Chem. Commun. 1997, 62, 1185.

140. Knoth W. H., Sauer J. C., England D. C., Hertler W. R., Muetterties E. L.: J. Am. Chem. Soc. 1964, 86, 3973.

141. Miller H. C., Hertler W. R., Muetterties E. L., Knoth W. H., Miller N. E.: Inorg. Chem. 1965, 4, 1216.

142. Jelínek T., Plešek J., Mareš F., Heřmánek S., Štíbr B.: Polyhedron 1987, 6, 1981.

143. Usyatinskii A. Y., Budkina K. V., Petrovskii P. V., Bregadze V. I.: Russ. Chem. Bull. 1995, 44,724 .

144. Bregadze V. I., Kampel V. T., Usiatinsky A. Y., Godovikov N. N.: Pure Appl. Chem. 1991, $63,357$.

145. Bregadze V. I., Kampel V. T., Godovikov N. N.: J. Organomet. Chem. 1977, 136, 281.

146. Yakushev A. B., Sivaev I. B., Solntsev K. A., Kuznetsov N. T.: Russ. J. Coord. Chem. 1994, 20, 404. 
147. Yakushev A. B., Sivaev I. B., Solntsev K. A., Kuznetsov N. T.: Koord. Khim. 1990, 16, 594 and 867.

148. Plešek J., Janoušek Z., Heřmánek S.: Inorg. Synth. 1983, 22, 241.

149. Plešek J., Janoušek Z., Heřmánek S.: Collect. Czech. Chem. Commun. 1978, 43, 1332.

150. Zakharkin L. I., Pisareva I. V.: Phosphorus Sulfur Rel. Elem. 1984, 20, 357.

151. Pakhomov S., Kaszynski P.: Unpublished results.

152. Komura M., Nakai H., Shiro M.: J. Chem. Soc., Dalton Trans. 1987, 1953.

153. Wright J., Kaczmarczyk A.: Inorg. Chem. 1973, 12, 1453.

154. Morris J. H., Brattsev V. A., Gaines D. F. in: Advances in Boron Chemistry (W. Siebert, Ed.), p. 434. The Royal Society of Chemistry, Bodmin (U.K.) 1997.

155. Echeistova A. I., Syrkin Y. K., Stanko V. I., Klimova A. I.: Russ. J. Struct. Chem. 1967, 8, 833.

156. Karcev G. N., Ignatieva C. M., Lebedev V. N., Zakharkin L. I.: Metalloorg. Khim. 1989, 2, 1398.

157. Knoth W. H., Sauer J. C., Balthis J. H., Miller H. C., Muetterties E. L.: J. Am. Chem. Soc. 1967, 89, 4842 .

158. Preetz W., Nachtigal C.: Z. Anorg. Allg. Chem. 1995, 621, 1632.

159. Shelly K., Knobler C. B., Hawthorne M. F.: Inorg. Chem. 1992, 31, 2889.

160. Dou D. N., Mavunkal I. J., Bauer J. A. K., Knobler C. B., Hawthorne M. F., Shore S. G.: Inorg. Chem. 1994, 33, 6432.

161. Zakharkin L. I., Kalinin V. N.: Russ. J. Gen. Chem. 1965, 35, 1878.

162. Alam F., Soloway A. H., Barth R. F., Mafune N., Adams D. M., Knoth W. H.: J. Med. Chem. 1989, 32, 2326.

163. Semioshkin A. A., Inyushin S. G., Artemov V. A., Petrovskii P. V., Bregadze V. I.: Russ. Chem. Bull. 1998, 47, 1778.

164. Zakharkin L. I., Lvov A. I., Grebennikov A. V.: Bull. Acad. Sci. U.S.S.R., Div. Chem. Sci. 1968, 2157.

165. Yang X., Hawthorne M. F.: Inorg. Chem. 1993, 32, 242.

166. Zakharkin L. I., Brattsev V. A., Chapovskii Y. A.: Russ. J. Gen. Chem. 1965, 35, 2149.

167. Zakharkin L. I., Chapovsky Y. A.: Tetrahedron Lett. 1964, 1147.

168. Stanko V. I., Klimova T. V.: Russ. J. Gen. Chem. 1977, 47, 1844.

169. Brown D. A., Colquhoun H. M., Daniels J. A., MacBride J. A. H., Stephenson I. R., Wade K.: J. Mater. Chem. 1992, 2, 793.

170. Scobie M., Threadgill M. D.: J. Chem. Soc., Perkin Trans. 1 1994, 2059.

171. Li J., Logan C. F., Jones M., Jr.: Inorg. Chem. 1991, 30, 4866.

172. Zakharkin L. I., Olshevskaya V. A.: Russ. J. Gen. Chem. 1987, 57, 317.

173. Zheng Z., Jiang W., Zinn A. A., Knobler C. B., Hawthorne M. F.: Inorg. Chem. 1995, 34, 2095.

174. Zakharkin L. I., Olshevskaya V. A.: Synth. React. Inorg. Met.-Org. Chem. 1991, 21, 1041.

175. Zakharkin L. I., Kovredov A. I., Olshevskaya V. A., Shaugumbekova Z. S.: J. Organomet. Chem. 1982, 226, 217.

176. Peymann T., Knobler C. B., Hawthorne M. F.: Inorg. Chem. 1998, 37, 1544.

177. Kovredov A. I., Shaugumbekova Z. S., Pertovskii P. V., Zakharkin L. I.: Russ. J. Gen. Chem. 1989, 59, 537.

178. Zakharkin L. I., Kovredov A. I., Olshevskaya V. A.: Bull. Acad. Sci. U.S.S.R., Div. Chem. Sci. 1981, 1775. 
179. Jiang W., Harwell D. E., Mortimer M. D., Knobler C. B., Hawthorne M. F.: Inorg. Chem. 1996, 35, 4355 .

180. Grüner B., Janoušek Z., King B. T., Woodford J. N., Wang C. H., Všetečka V., Michl J.: J. Am. Chem. Soc. 1999, 121, 3122.

181. Zakharkin L. I., Olshevskaya V. A., Zhigareva G. G.: Russ. J. Gen. Chem. 1998, 68, 925.

182. Zakharkin L. I., Balagurova E. V., Ledebev V. N.: Russ. J. Gen. Chem. 1998, 68, 922.

183. Zakharkin L. N., Kalinin V. N.: Bull. Acad. Sci. U.S.S.R., Div. Chem. Sci. 1971, 2185.

184. Zakharkin L. I., Kalinin V. N., Gedymin V. V.: Bull. Acad. Sci. U.S.S.R., Div. Chem. Sci. 1970, 1157.

185. Stanko V. I., Goltyanin Y. V., Brattsev V. A.: Russ. J. Gen. Chem. 1967, 37, 2247.

186. Grushin V. V.: Acc. Chem. Res. 1992, 25, 529; and references therein.

187. Grushin V. V., Demkina I. I., Tolstaya T. P.: J. Chem. Soc., Perkin Trans. 2 1992, 505.

188. Zakharkin L. I., Sulaimankulova D. D., Pisareva I. V.: Metallorg. Khim. 1990, 3, 910.

189. Bregadze V. I., Kampel V. T., Godovikov N. N.: J. Organomet. Chem. 1978, 157, C1.

190. Bregadze V. I., Usyatinskii A. Y., Godovikov N. N.: Bull. Acad. Sci. U.S.S.R., Div. Chem. Sci. 1981, 315.

191. Bregadze V. I., Usyatinskii A. Y., Godovikov N. N.: Bull. Acad. Sci. U.S.S.R., Div. Chem. Sci. 1979, 2642.

192. Peymann T., Lork E., Gabel D.: Inorg. Chem. 1996, 35, 1355.

193. Gabel D., Moller D., Harfst S., Rösler J., Ketz H.: Inorg. Chem. 1993, 32, 2276.

194. Zakharkin L. I., Pisareva I. V., Agakhanova T. B.: Bull. Acad. Sci. U.S.S.R., Div. Chem. Sci. 1978, 2529.

195. Zakharkin L. I., Kovredov A. I., Olshevskaya V. A., Antonovich V. A.: J. Organomet. Chem. 1984, 267, 81.

196. Zakharkin L. I., Olshevskaya V. A., Antonovich V. A.: Russ. J. Org. Chem. 1987, 23, 1513.

197. Hawthorne M. F., Berry T. E., Wegner P. A.: J. Am. Chem. Soc. 1965, 87, 4746.

198. Zakharkin L. I., Kalinin V. N.: Bull. Acad. Sci. U.S.S.R., Div. Chem. Sci. 1965, 2173.

Collect. Czech. Chem. Commun.

1999, 64, 895-926

\section{Four Decades of Organic Chemistry}

of closo-Boranes: A Synthetic Toolbox

for Constructing Liquid Crystal Materials.

A Review

Piotr Kaszynski

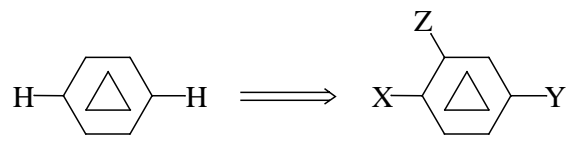

